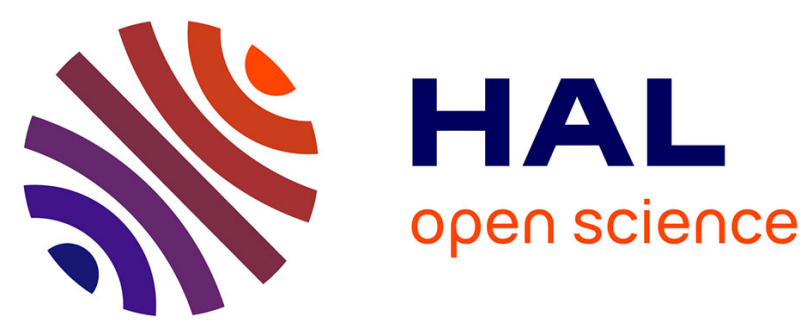

\title{
A metabolic study of the regulation of proteolysis by sugars in maize root tips: effects of glycerol and dihydroxyacetone
}

Renaud Brouquisse, Dominique Rolin, Sandra Cortès, Monique Gaudillère, Adeline Evrad, Claude Roby

\section{To cite this version:}

Renaud Brouquisse, Dominique Rolin, Sandra Cortès, Monique Gaudillère, Adeline Evrad, et al.. A metabolic study of the regulation of proteolysis by sugars in maize root tips: effects of glycerol and dihydroxyacetone. Planta, 2007, 225 (3), pp.693 - 709. 10.1007/s00425-006-0378-x . hal-00106242

\section{HAL Id: hal-00106242 \\ https://hal.science/hal-00106242}

Submitted on 16 Oct 2006

HAL is a multi-disciplinary open access archive for the deposit and dissemination of scientific research documents, whether they are published or not. The documents may come from teaching and research institutions in France or abroad, or from public or private research centers.
L'archive ouverte pluridisciplinaire $\mathbf{H A L}$, est destinée au dépôt et à la diffusion de documents scientifiques de niveau recherche, publiés ou non, émanant des établissements d'enseignement et de recherche français ou étrangers, des laboratoires publics ou privés. 
Renaud Brouquisse, Dominique Rolin, Sandra Cortès, Monique Gaudillère, Adeline Evrard, Claude Roby

\section{A metabolic study of the regulation of proteolysis by sugars in maize root tips: effects of glycerol and dihydroxyacetone}

Unité Mixte de Recherche de Physiologie et Biotechnologie Végétales, Institut National de la Recherche Agronomique, Université de Bordeaux 1 and Université Victor Ségalen Bordeaux 2, IFR 103, BP 81, 33883 Villenave d'Ornon cedex, France. (RB, DR, MG)

Unité Mixte de Recherche de Physiologie Cellulaire Végétale, Commissariat à l'Energie Atomique, Centre National de la Recherche Scientifique, Institut National de la Recherche Agronomique, and Université Joseph Fourier, CEA-Grenoble, 17 rue des Martyrs, 38054 Grenoble cedex 9, France. (RB, SC, AE, CR)

Corresponding author:

Renaud Brouquisse

Tel : (33) 438782907

Fax : (33) 438785091

Email : renaud.brouquisse@cea.fr 


\begin{abstract}
Sugars, the main growth substrates of plants, act as physiological signals in the complex regulatory network of sugar metabolism. To investigate the function of different glycolytic steps in sugar sensing and signalling we compared the effects of carbon starvation with those of glucose, glycerol and dihydroxyacetone on carbon metabolism, proteolysis, and protease expression in excised maize (Zea mays L.) root tips. Respiration, soluble proteins, protein turnover and proteolytic activities were monitored as a function of time, along with in-vitro and in-vivo analysis of a variety of metabolites (sugars, amino and organic acids, phosphoesters, adenine nucleotides...) using ${ }^{13} \mathrm{C},{ }^{31} \mathrm{P}$ and ${ }^{1} \mathrm{H}$ NMR spectroscopy. Our results indicate that, in maize root tips, endopeptidase activities and protease expression are induced in response to a decrease in carbon supply to the upper part of the glycolytic pathway, i.e. at the hexokinase step. Proteolysis would be controlled downstream glycolysis, probably at the level of the respiratory substrate supply to mitochondria.
\end{abstract}

\title{
Keywords
}

Dihydroxyacetone; Glycerol; Metabolic NMR; Proteolysis regulation; Sugar sensing; Zea

\begin{abstract}
Abbreviations
AdN: adenine nucleotides; AEC: adenylate energy charge; DHA: dihydroxyacetone; EP: endopeptidase; Glc: glucose; G6P: glucose-6-P; Glyc: glycerol; Glyc3P: glycerol-3-P; MDP : methylenediphosphonic acid; NMR: nuclear magnetic resonance; NPB: net protein balance; 3OMG: 3-O-methylglucose; PD: protein degradation; PEP: phosphoenolpyruvate; PEPCase: phosphoenolpyruvate carboxylase; P-chol: phosphorylcholine; P-eth: phosphorylethanolamine; 3PGA: 3-phosphoglycerate; PK: pyruvate kinase; PS: protein synthesis; RSIP: root starvation induced protease; Suc: sucrose; TMS : tetramethylsilane; TSP : 3-trimethylsilylpropionic-2,2,3,3d4 acid sodium salt; UDPG: uridine diphosphoglucose.
\end{abstract}




\section{Introduction}

In plants, the variable supply of sugars to growing tissues has an effect on development and metabolism through modifications of enzyme activities and gene expression (Koch 2004; Gibson 2005). Under environmental constraints leading to a significant decrease in photosynthesis, such as during senescence, in post-harvest situations, or when competition occurs between sink tissues, various parts of a plant might be temporarily or definitively subjected to carbon starvation (Brouquisse et al. 1998; Yu 1999). Survival is correlated with the substitution of protein and lipid catabolism for sugar metabolism through autophagic processes (Saglio and Pradet 1980; Brouquisse et al. 1991; Contento et al. 2004). Thus, while the expression and activity of most of the enzymes related to sugar metabolism, nitrogen assimilation, respiration, and cell division decrease, those of enzymes related to the catabolism of proteins, amino acids, and lipids increase (Brouquisse et al. 1992; Dieuaide et al. 1993; James et al. 1993; Fujiki et al. 2000; Hanaoka et al. 2002; Lee et al. 2004; Contento et al. 2004; Price et al. 2004). It is clear that changes in selective synthesis or degradation of given proteins could be important in the coordinated response to carbon restriction (Koch 1996; Yu 1999).

In plant cells, as in yeast or animal cells, protein degradation could be mediated by several populations of proteases involved in various catabolic processes: (i) lysosomal/vacuolar proteolysis, (ii) selective nuclear and cytosolic proteolysis, and (iii) organellar proteolysis (Smalle and Viertsra 2004; Schaller 2004). Vacuolar autophagy has been observed in plant cells submitted to sugar deprivation (Aubert et al. 1996; Moriyasu and Oshumi 1996; Hanaoka et al. 2002). In excised maize root tips, a vacuolar serine endopeptidase (EP) is induced in response to glucose (Glc) starvation (James et al. 1996). This protease, named Root Starvation Induced Protease (RSIP), accounts for about $80 \%$ of the total EP activity in the starved roots (James et al. 1996; Brouquisse et al. 1998, 2001). Cysteine protease and chymotrypsin/subtilisin-like protease inhibitor are also induced in sugar starved maize root tips (Chevalier et al. 1995). The induction of the proteolytic activities by the lack of carbohydrates can be reversed by the addition of sugars in the incubation medium (James et al. 1993; Chevalier et al. 1995). Thus, since the expression of these enzymes is directly related to the cellular sugar supply, the next step was to study how protease expression and protein degradation processes are regulated by sugars in plant cells.

The mechanisms used by living cells to sense sugars have been extensively studied in yeast (Rolland et al. 2001) and, there is ample evidence that sugar-sensing mechanisms are globally conserved in animal and plant cells (Hanson 2000; Rolland et al. 2002; Koch 2004; 
Gibson 2005). The use of sugars, non metabolizable sugar analogs, or metabolic intermediates, showed that there are several potential locations for signal input into the sugar sensing system. Following the common catabolic pathway of sugars, the first potential sensing step is their translocation through the plasma membrane. In Saccharomyces cerevisiae, Glc transporters SNF3 and RGT2 act as sugar sensors which mediate the activation of different sets of other Glc transporter genes (Ozcan and Johnston 1999). In plants, among the 59 sugar transporters putatively identified, some sugar transporter-like proteins could act as sugar sensors analogous to SNF3 or RGT2 (Price et al. 2004). In sugar beets the proton-sucrose symport is regulated by Suc (Chiou and Bush 1998). In Arabidopsis thaliana, the expression of Leu zipper gene, ATB2, is assumed to be controlled by the influx of Suc into the cell (Rook et al. 1998), and the patatin class 1 promoter is induced by 6-deoxyglucose and 3-O-methylglucose (3-OMG), two Glc analogs actively taken up by the cells but not metabolized further (Martin et al. 1997; Rolland et al. 2002; Cortès et al. 2003). Furthermore, in Chenopodium rubrum, the genes encoding sucrose synthase and apoplastic invertase are induced by 6-deoxyglucose (Roitsch et al. 1995, 2003). However, in these latter cases, it is not possible to determine if the sugar signal is generated by the sugar influx through the transporter or by the intracellular concentration of the sugar itself and/or its potential interaction with a sugar-binding protein endowed with a signaling function (Gibson 2005). Intracellular hexose concentration might be another sugar sensing element but, to date, no methodology can reliably give access to the sugar concentrations in the different compartments of the living cell. The next sensing step, and certainly the more extensively investigated, is the phosphorylation of hexoses by hexokinases. In yeast (Rolland et al. 2001), as well as in bacteria (Saier et al. 1995), animal (Hanson 2000) or plant (Moore et al. 2003) cells, numerous studies have shown that the hexokinase is a major sugar sensing element, conserved in eukaryotes and procaryotes, which control diverse processes and metabolic pathways. Using nonmetabolizable sugar analogs and an hexokinase inhibitor, it was demonstrated that the sugar repression of the glyoxylate cycle genes, malate synthase (MS) and isocitrate lyase (ICL), in nongreen cucumber cells, was mediated by hexokinase (Graham et al. 1994). Similar results were found in maize protoplasts with the repression by sugars of the transcription of three photosynthetic genes, rubisco small subunit (RBCs), chlorophyll a/b binding protein (CAB) and pyruvate phosphate dikinase $\left(\mathrm{C}_{4} \mathrm{PPDK}\right)$ (Jang and Sheen 1994). The role of hexokinase as a sugar sensor in the control of growth and development was demonstrated later from the cloning of two Arabidopsis thaliana hexokinase genes (AtHXK1 and 2) using AtHXK1 and 2 transformed plants and HXK1 mutants (Jang et al. 1997; Moore et al. 2003). 
The role played by the enzymes of Suc breakdown (invertase, sucrose synthase) and trehalose metabolism (trehalose-P synthase, trehalose-P phosphatase, trehalase) in the sugar regulation of growth and development has also been studied (Eastmond and Graham 2003; Koch 2004). Thus, the expression of yeast invertase in either apoplasm, cytosol or vacuole of transgenic tobacco plants led to elevated levels of fructose and Glc in these compartments (Hebers et al. 1996). However, high hexose levels altered gene expression only in plants expressing invertase in the apoplasm or the vacuole, but not in plants expressing invertase in the cytosol. It was proposed that hexose sensing mechanisms are located at the secretory membrane system (Hebers et al. 1996). From all these experiments it was hypothesized that both hexose translocation and phosphorylation are necessary to trigger a sugar signal. More recently, trehalose-6-P has been shown to regulate plant growth and carbon utilization through the regulation of glycolysis (Schluepmann et al. 2003). The knockout mutation of the trehalose-P synthase (TPS1) gene was found to be lethal for Arabidopsis embryos when storage reserves are remobilized and sugars are supplied to the embryos (Eastmond and Graham 2003). Interestingly, the expression of some trehalose-P synthase and trehalose-P phosphatase genes are up-regulated in Suc starved Arabidopsis cells (Contento et al. 2004). Such observations strongly suggest that trehalose-6-P is involved in sugar sensing in plants, but underlying mechanisms by which it regulates carbon metabolism are still unknown.

In animals, downstream metabolites in the glycolytic pathway are essential for Glc sensing in pancreatic islet beta cells (Hanson 2000). By analogy, it has be inferred that, downstream hexokinase, certain metabolites or enzymes in the glycolytic pathway trigger sugar sensing signals in plants. Thus, in maize protoplasts, glycerol (Glyc) repressed $\mathrm{C}_{4} \mathrm{PPDK}$, and acetate, which presumably enters the respiration or the glyoxylate cycle via acetyl-CoA, repressed $\mathrm{C}_{4} \mathrm{PPDK}, \mathrm{CAB}$ and $\mathrm{RBCs}$ (Sheen 1990). Conversely, acetate induced MS and ICL gene expression in cucumber cells (Graham et al. 1994). In rice cells, pyruvate, the main mitochondrial substrate derived from glycolysis, repressed sugar down-regulated genes ( $\alpha A m y 3$ and A3), but did not activate the expression of sugar up-regulated genes (Ho et al. 2001). Sugarstarved sycamore cells incubated in the presence of Glyc or pyruvate stopped growing but were able to survive for weeks in the absence of any gluconeogenesis and did not display autophagy symptoms (Aubert et al. 1994, 1996). The conclusion of that study was that the decline in the supply of respiratory substrate to mitochondria was triggering autophagy in carbon-starved cells (Aubert et al. 1996). However, it is still unknown if such a signal controls only metabolic processes or if it also regulates gene expression. Key metabolites such as fructose 2,6 bis- 
phosphate, ester phosphates, adenine nucleotides (AdN) or $\mathrm{Pi} / \mathrm{PPi}$ ratio, which regulate carbohydrate metabolism, appear to be little or not at all involved in sugar regulation of gene expression in the systems studied so far (Stitt et al. 1995).

Questionning the role of hexokinase as sugar sensor it was suggested that in plants, like in yeast, changes in AdN contents or ratios (i.e. ATP/ADP and ATP/AMP) could affect the level of almost any cellular metabolite and thus could be involved in the regulation of sugar signal transduction (Halford et al. 1999). Such an effect has been shown to occur in developing barley seeds, where higher ATP levels were found in tissues in which storage starch is beginning to form (Rolletschek et al. 2004). Inorganic phosphate was also reported to inhibit the expression of sugar-inducible genes encoding vegetative storage protein, lipoxygenase A, chalcone synthase, proteinase inhibitor II and class I patatin, in the presence or absence of sugars (Sadka et al. 1994), and could be part of, or directly interact with, sugar sensing mechanisms. However, Pi did not relieve the repression by sugars of genes involved in glyoxylic cycle (Graham et al. 1994), photosynthesis (Jang and Sheen 1994), or proteolysis (Brouquisse et al. 2001).

We showed previously that, in maize root tips, mannose might be considered to have the same down-regulation effect on proteolysis as Glc, provided that Pi status is maintained (Brouquisse et al. 2001). We later showed that, although very slowly phosphorylated by hexokinase, 3-OMG does not repress proteolysis (Cortès et al. 2003). This led us to hypothesize that hexokinase is a possible sensor involved in the regulation of proteolysis by sugars. In the present work, we looked for the occurrence of a potential sugar sensing step, downstream hexokinase, for the regulation of protease expression and the control of protein degradation processes. For this purpose, we investigated the regulation of protease expression and protein degradation in excised maize root tips, by studying the effects of carbon starvation, Glyc, and DHA, on general metabolism, proteolysis, and RSIP expression. Using in-vitro and in-vivo ${ }^{13} \mathrm{C}$ and ${ }^{31} \mathrm{P}$ NMR spectroscopy, together with physiological and biochemical measurements, we measured the concentrations of various metabolites (sugars, ester-phosphates, AdN, amino acids and proteins), changes in respiration rate, proteolytic activities and RSIP amounts.

\section{Materials and methods}

Plant materials and incubation conditions 
Maize seeds (Zea Mays L. cv DEA, from Pioneer France Maïs, Toulouse, France) germination, root tip preparation and incubation conditions have already been described (Brouquisse et al. 2001). Incubation medium A was composed of a mineral medium (Saglio and Pradet 1980), plus $10 \mathrm{mM}$ Mes-KOH at $\mathrm{pH}$ 6.0. Root tip $(2.5 \mathrm{~mm})$ samples were either perfused in the NMR tube for in-vivo measurements or incubated in flasks or syringes for tissue extraction, in the presence or absence of Glyc, DHA, mannitol, 3-OMG or Glc. To monitor growth, samples of 20 root tips were harvested at different times, dried on filter paper, weighed on tinfoil, and root tip lengths were measured. In-vivo NMR experiments were performed as described (Brouquisse et al. 2001) except that 4000 excised root tips were used for each experiment and the partial oxygen pressure was regulated at $80 \%$ in the reservoir of external medium. The renewal of the medium around the sample varied from 24 to eight times a minute between the start and the end of the experiment, because of the growth (the average root tip length was $2.5 \mathrm{~mm}$ at the start and $3.7 \mathrm{~mm}$ after $48 \mathrm{~h}$ for the Glyc or DHA-fed samples).

Measurement of root tip respiration

Maize root tip respiration was measured at $23{ }^{\circ} \mathrm{C}$ in medium A, supplemented with or without carbon sources (Glc, 3-OMG, DHA, Glyc), with a Clark type $\mathrm{O}_{2}$-electrode system (Transidyne General Corporation, Ann Arbor, Michigan). Five to ten root tips were transferred into $1.5 \mathrm{ml}$ of incubation medium previously flushed with pure $\mathrm{O}_{2}$, and $\mathrm{O}_{2}$-consumption was monitored for 15 $\min$.

In-vivo protein radiolabeling and protein turnover measurement

Protein synthesis (PS) and protein degradation (PD) were determined by pulse-chase experiments after in-vivo labeling of the proteins with either $\left[{ }^{35} \mathrm{~S}\right]$ Met or $\left[{ }^{14} \mathrm{C}\right]$ Leu. One thousand excised maize root tips were incubated as described above in $250 \mathrm{ml}$ of medium A supplemented with $200 \mathrm{mM} \mathrm{Glc}$, antibiotics-antimycotics, and either $5 \mathrm{mM}\left[{ }^{35} \mathrm{~S}\right] \mathrm{Met}(30 \mathrm{MBq} / \mathrm{mmol})$ or $5 \mathrm{mM}$ $\left[{ }^{14} \mathrm{C}\right]$ Leu $(1.48 \mathrm{MBq} / \mathrm{mmol})$. After $24 \mathrm{~h}$, root tips were abundantly rinsed with medium A supplemented with $5 \mathrm{mM}$ cold Met or Leu, and then incubated for $48 \mathrm{~h}$ in medium A containing $5 \mathrm{mM}$ cold Met or Leu, antibiotics-antimycotics, either without carbon source, or in the presence of $100 \mathrm{mM}$ Glyc, $100 \mathrm{mM}$ DHA or $200 \mathrm{mM}$ Glc. Samples of 25 root tips were harvested every 6 $\mathrm{h}$, rinsed with distilled water and frozen in liquid $\mathrm{N}_{2}$. Proteins of the root tips were extracted in a 
glass Potter with $500 \mu \mathrm{l}$ of an extraction medium containing $50 \mathrm{mM}$ Tris, $\mathrm{pH}$ 7.4, $25 \mathrm{mM} \mathrm{NaCl}$, $0.1 \%(\mathrm{p} / \mathrm{v})$ Triton $\mathrm{X} 100$, and $5 \mathrm{mM} \beta$-mercaptoethanol. The crude extract was centrifuged at 25 $000 \mathrm{~g}$ for $12 \mathrm{~min}$, and the resulting supernatant was supplemented to $1 \mathrm{ml}$ with water. It constituted the clarified extract. Five hundred microliters of the clarified extract were then desalted through an ECONO-PAC 10 DG column (Bio-Rad Laboratories, Hercules, CA) equilibrated with $50 \mathrm{mM}$ Tris, $\mathrm{pH} 7.5$, and $\mathrm{NaCl} 25 \mathrm{mM}$. Aliquots of the clarified extract were used to determine total soluble proteins (P) and aliquots of the desalted extracts were used to determine the specific radioactivity and the total radioactivity (RA) of the soluble proteins. Radioactivity was measured in a liquid scintillation analyzer (TRICARB 2000 CA, Packard, Palo Alto, CA). Over $6 \mathrm{~h}$ incubation periods, from initial (i) to final (f) time, net protein balance $(\mathrm{NPB})$ and PD were determined as follows : NPB $=\mathrm{P}_{\mathrm{f}}-\mathrm{P}_{\mathrm{i}} ; \mathrm{PD}=\mathrm{P}_{\mathrm{i}}\left[1-\left(\mathrm{RA}_{\mathrm{f}} / \mathrm{RA}_{\mathrm{i}}\right)\right]$. PS was calculated as the difference between PD and NPB (PS = PD - NPB).

\section{Preparation of extracts}

Metabolite and enzymic extracts were prepared from root tip samples incubated either for $4 \mathrm{~h}$ in $200 \mathrm{mM} \mathrm{Glc}$, or for $48 \mathrm{~h}$ in medium A supplemented with or without $100 \mathrm{mM}$ Glyc, $100 \mathrm{mM}$ DHA or $200 \mathrm{mM} \mathrm{Glc.}$

Clarified homogenates of maize root tips. Clarified homogenates were prepared as described (Brouquisse et al. 2001). Before enzyme activity measurements and immunoprecipitation experiments, 0.5 to $1 \mathrm{ml}$ of supernatant was first desalted through an ECONO-PAC 10 DG column equilibrated with $50 \mathrm{mM}$ Tris, $\mathrm{pH} 7.5$, and $25 \mathrm{mM} \mathrm{NaCl}$.

Acid and ethanolic extracts of maize root tips. Water soluble metabolites were extracted either from two thousand excised root tips using perchloric acid (Brouquisse et al. 2001), or from two hundred excised root tips using hot ethanol (Brouquisse et al. 1992). Acid extracts were used for ${ }^{13} \mathrm{C}$ and ${ }^{31} \mathrm{P}$ analysis. ${ }^{13} \mathrm{C}$ NMR spectra were recorded first. For ${ }^{31} \mathrm{P}$ NMR, trans-1,2diaminocyclohexane-N,N,N',N'-tetraacetic acid (CDTA) was added to chelate divalent cations and the $\mathrm{pH}$ was adjusted to the desired value. Ethanolic extracts were used for ${ }^{1} \mathrm{H}$ NMR analysis.

PEP and 3PGA extraction and analysis

Two hundred root tip samples were first lyophilized, and then extracted successively with $2 \mathrm{ml}$ $80 \%(\mathrm{v} / \mathrm{v})$ acetone, $50 \%(\mathrm{v} / \mathrm{v})$ acetone and pure water at ambient temperature for $15 \mathrm{~min}$. The 
three supernatants were combined and centrifuged for $10 \mathrm{~min}$ at $25000 \mathrm{~g}$. The resulting supernatants were dried under vacuum for one night, and the dry residues were resuspended in $0.4 \mathrm{ml}$ of water. PEP and 3PGA were determined using anion exchange HPLC (Dionex, Voisin le Bretonneux, France) with conductivity detection. Elution conditions were adapted from Vogt et al. (1998).

Enzyme activity assays

EP activities were measured, at $\mathrm{pH}$ 6.1, against azocasein as described (James et al. 1993). The extinction coefficient $\mathrm{E}_{1 \%} \%$ azocaseine in $1 \mathrm{M} \mathrm{NaOH}=37 \mathrm{~cm}^{-1} \mathrm{~g}^{-1}$ was used to calculate the azocaseinase activity. Phosphoenolpyruvate-carboxylase (PEPCase) activity assay was adapted from Brouquisse et al. (1991). Except when mentioned, the assay medium contained the enzymic extract, $50 \mathrm{mM}$ tricine, $\mathrm{pH} 8.3,5 \mathrm{mM} \mathrm{MgCl}_{2}, 0.2 \mathrm{mM} \mathrm{NADH}, 5$ units malate dehydrogenase, and $10 \mathrm{mM} \mathrm{NaHCO}$. The reaction was initiated with $5 \mathrm{mM}$ phosphoenolpyruvate (PEP) and monitored at $340 \mathrm{~nm}$. PEP phosphatase activity was coupled with lactate dehydrogenase reaction and analyzed as in Duff et al. (1989). Pyruvate kinase (PK) activity assay was adapted from Podesta and Plaxton (1994). Except when mentioned, the assay medium contained enzymic extract, $50 \mathrm{mM}$ Hepes, pH 7.5, $10 \mathrm{mM} \mathrm{MgCl}$, $40 \mathrm{mM} \mathrm{KCl,} 2 \mathrm{mM}$ DTT, $0.2 \mathrm{mM}$ NADH, 5 units lactate dehydrogenase, $500 \mu \mathrm{M}$ sodium molybdate (a PEP phosphatase inhibitor), and $2 \mathrm{mM}$ ADP. Reaction was initiated with $1 \mathrm{mM}$ PEP and monitored at $340 \mathrm{~nm}$. Hexokinase activity was measured as described (Brouquisse et al. 1991).

Other analytical methods

Proteins were quantified (Bradford 1976) using the Bio-Rad microassay reagent. Bovine $\gamma$ globulin was used as the protein standard. SDS-PAGE, western-blot and immunoprecipitation experiments were performed as described (Brouquisse et al. 2001). AdN were extracted by the cold diethyl-ether/trichloroacetic acid procedure and determined by the bioluminescence method (Saglio and Pradet 1980). Adenylate energy charge (AEC) was calculated as follows: AEC = $(\mathrm{ATP}+0.5 \mathrm{ADP}) /(\mathrm{ATP}+\mathrm{ADP}+\mathrm{AMP})($ Pradet and Raymond 1983).

NMR spectroscopy 
Carbon and phosphorous NMR. ${ }^{31} \mathrm{P}$ and ${ }^{13} \mathrm{C}$ NMR spectra were acquired at 162 and $100.6 \mathrm{MHz}$ respectively using an AMX400 WB spectrometer (Bruker Biospin., Wissembourg, France). For in-vivo experiments, they were recorded alternatively for 10 and $50 \mathrm{~min}$ respectively, using a dual electronically-switched $25 \mathrm{~mm}$ probe. Acid extracts were analyzed using a $10 \mathrm{~mm}$ broadband probe. A solution composed of $50 \mathrm{mM}$ methylenediphosphonic acid (MDP, ref 9508, Sigma) and 1.3 M 3-Trimethylsilylpropionic-2,2,3,3-d4 acid sodium salt (TSP, ref 87247 Fluka) contained in a concentric capillary provided the chemical shifts and intensity references for ${ }^{31} \mathrm{P}$ and ${ }^{13} \mathrm{C}$ NMR spectra. The resonance assignments were based on chemical shifts. Specific acquisition conditions are given in the figure legends (supplemental data) and below.

Carbon chemical shifts were referenced to tetramethylsilane (TMS) using the Suc fructosyl C2 resonance (C2f) fixed at $104.4 \mathrm{ppm}$ as a secondary internal reference. In the absence of Suc resonances in a spectrum, the resonance of TSP contained in the capillary mixture was used as secondary external reference (chemical shift measured at - $1.47 \mathrm{ppm}$ ). The metabolite amounts were determined from the NOE-free intensities of the following resonances of acid extract relaxed spectra: $\mathrm{C} 2 \mathrm{f}$ for Suc, $\mathrm{C} 1 \beta$ for glc and $\beta \mathrm{CH}$ for Asn. The absolute metabolite amounts were calculated using the TSP resonance intensity calibrated in moles.

Phosphorous chemical shifts were referenced to $85 \% \mathrm{H}_{3} \mathrm{PO}_{4}$ using internal GPC as a secondary reference (- $0.05 \mathrm{ppm})$ for in-vitro spectra and internal UDPG (- $12.65 \mathrm{ppm})$ for invivo spectra (the chemical shift of MDP contained in the capillary mixture was measured at $16.72 \mathrm{ppm})$. Quantifications of acid extract spectra were done by integration of the resolved, NOE-free, relaxed resonances and calibration of the intensities was achieved using the resonance intensity of MDP. The concentration time courses of cyt-Pi and vac-Pi were obtained in-vivo in the following way. First, the intensities of the assigned resonances were measured in each spectrum, eventually corrected to take sample growth out of the detection coil into account, as well as spectral fluctuations, and plotted as a function of time. Second, the curve obtained was calibrated against concentration using the NOE-free intensities of a relaxed spectrum of maize root tips fed on $200 \mathrm{mM}$ Glc and the MDP reference.

Proton NMR. ${ }^{1} \mathrm{H}-\mathrm{NMR}$ spectra of extracts were recorded at $500.16 \mathrm{MHz}$ and $300 \mathrm{~K}$ using an Avance spectrometer (Bruker Biospin), a $5 \mathrm{~mm}$ inverse probe and XWINNMR software (Bruker Biospin). TSP was added in each sample to a final concentration of $0.01 \%$ for chemical shift calibration. Relaxed spectra were obtained by adding 64 FID's acquired with a resolution of 
$0.1 \mathrm{~Hz}$, a $90^{\circ}$ pulse angle, an acquisition time of $2.73 \mathrm{~s}$ and a relaxation delay of $20 \mathrm{~s}$. An exponential apodisation with $0.5 \mathrm{~Hz}$ line broadening was used. Absolute quantification of metabolite concentrations was achieved using the ERETIC method during acquisition (Akoka et al. 1999) and the metabolite mode of AMIX (Bruker Biospin) to measure resonance areas. The metabolite concentrations were calculated in Excel using the $\mathrm{C} 1 \mathrm{H}-(\alpha+\beta)$ Glc calibration curve.

\section{Results}

To investigate the effects of Glyc and DHA on maize root tips metabolism, proteolysis and RSIP expression, a 48-h incubation period was chosen because the changes in enzymatic activities and metabolite contents induced were clearly marked while remaining fully reversible (Brouquisse et al. 2001; Cortès et al. 2003).

Effects of various carbon sources on protein content and proteolytic activities

Maize root tips were incubated in the presence of either Glc, mannitol (used as an osmotic control), Glyc or DHA. The phosphorylated forms of Glyc and DHA enter glycolysis downstream hexokinases. Fig. 1a reports the changes in total protein content and EP activities (measured against azocasein) which occured in maize root tips after $48 \mathrm{~h}$ incubation in the presence of the different substrates, in comparison to the control $(\mathrm{Ctrl})$ and to the starvation situation (Star). Increasing concentrations of Glc in the incubation medium led to decreased EP

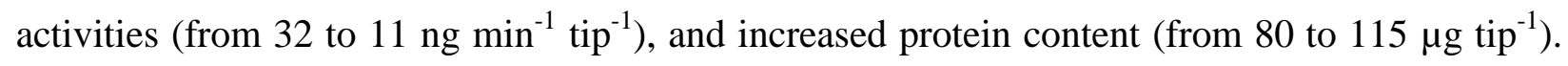
In the presence of mannitol, and to a lesser extent Glyc, protein content decreased to 63-84 $\mu \mathrm{g}$ tip $^{-1}$ and EP activities increased to $39-48 \mathrm{ng} \mathrm{min}^{-1} \mathrm{tip}^{-1}$ relative to the control and similar to what was observed in starved tips. In tips treated with 10 to $100 \mathrm{mM}$ DHA, the protein contents decreased only moderately (110-118 $\mu \mathrm{g} \mathrm{tip}^{-1}$ ), but EP activities increased to the same extent as in Glyc-treated material (37-40 $\mathrm{ng} \mathrm{min}^{-1} \mathrm{tip}^{-1}$ ). In the presence of $200 \mathrm{mM} \mathrm{DHA}$, practically no net protein degradation and no increase in EP activities occurred. This was probably due to the toxic effect of DHA at this concentration (important drop of the respiration and browning of the tips).

These results were used to foster the next experiments on the induction of RSIP. Each substrate was used at only one concentration for $48 \mathrm{~h}$. Two hundred $\mathrm{mM}$ Glc is the supply necessary to maintain the respiration rate of excised root tips at the control level (Saglio and 
Pradet 1980). Glyc, which exhibited similar effects on protein degradation and protease induction at 100 and $200 \mathrm{mM}$, was used at $100 \mathrm{mM}$. DHA was used at the same concentration. Since supplementation of the incubation medium with mannitol as osmolyte did not induce any difference in respiration rate or proteolysis (data not shown) the experiments were carried out without mannitol. Statistical analyses were performed on the results obtained in these four conditions (Control, starvation, $100 \mathrm{mM}$ Glyc, and $100 \mathrm{mM}$ DHA). The protein contents were found to be significantly different between starvation, Glyc and DHA conditions (Fig. 1a, label $\mathrm{x}$ ), whereas EP activities were not (Fig. 1b, label y).

The contribution of RSIP to EP activities was estimated through immunoprecipitation experiments using polyclonal antibodies raised against RSIP. RSIP was barely present in root tips freshly excised or incubated with Glc, and represented 14 to $28 \%$ of the total EP activities (Fig. 1b). In root tips, either starved or incubated with Glyc or DHA, the increase in total EP activity was related to a strong increase in the amount of RSIP which was shown to represent 76 to $82 \%$ of the EP activities. From these data, the calculated induction factors for RSIP in starved, or DHA or Glyc incubated tips were about 22 to 28 -fold (Fig. 1b).

Effects of various carbon sources on protein turnover

At any time, the protein content (Fig. 1a) is a static figure resulting from a balance between protein degradation and synthesis. To assess protein turnover, the rates of global protein degradation and synthesis were determined from a label-chase experiment. As shown in Fig. 2, when Glc is removed from the incubation medium, or replaced by Glyc or DHA, there is an immediate and significant increase in both PD rates (white bars) and PS rates (hatched bars). The initial and transient boost in PS and PD might be related to the acclimation processes triggered by the sudden change in carbon substrate and the induction of alternative metabolic pathways (Brouquisse et al. 1991, 1992; Dieuaide et al. 1993; James et al. 1993, 1996). After 6 to 12 hours, the rates of PS and PD declined to reach a quasi steady state between 18 and $48 \mathrm{~h}$ of incubation. Immediately after the change in substrate supply and up to $48 \mathrm{~h}$ of incubation, the NPB was in favour of degradation (Fig. 2, black bars). This indicates that neither Glyc, nor DHA, can efficiently support PS in maize root tips. The values of total PD, PS and NPB were also calculated over a $48 \mathrm{~h}$ incubation period in the three conditions (Table 1). Absolute value of NPB was significantly higher in starved root tips than in Glyc-fed ones, and in Glyc-fed root tips than in DHA-fed ones. These NPB differences were primarily due to differences in PD rates (20 and 
$30 \%$ higher in starved root tips than in Glyc- and DHA-treated root tips, respectively), since PS rates were in the same range in the three conditions (Table 1). This means that the changes in protein contents (Fig. 1a, label x) are representative of global PD occurring in these conditions (Fig. 2, Table 1).

In summary, our results show that EP activities and RSIP expression increase to the same extent in sugar-starved, Glyc-fed and DHA-fed root tips (Fig. 1a, b), but not proteolysis (Fig. 2). This discrepancy between protease expression and proteolysis might be due to the fact that the two processes are differentially regulated, and/or to specific secondary effects of Glyc and DHA. This led us to investigate the growth and some aspects of the primary metabolism of maize root tips in response to either Glyc or DHA supply.

Effects of glycerol and DHA on root tip growth and energetic metabolism

The growth of excised maize root tips incubated with $100 \mathrm{mM}$ of either Glyc or DHA was very limited compared with that of 50, 100 or $200 \mathrm{mM}$ Glc-fed tips, and similar to that observed in sugar starvation (Fig. 3). The slight increase in mass and the related increase in length, observed during the first 15 to $20 \mathrm{~h}$ of incubation, could be due to the consumption of endogenous sugars and water uptake resulting from the increase in cell osmolarity (Brouquisse et al. 1991).

After a 48 h-incubation period, the respiration rate of carbon-starved root tips dropped by $71 \%$ relatively to the control, whereas that of Glyc-fed and DHA-fed root tips only dropped by $60 \%$, and 46\% respectively (Table 2). Thus, Glyc and DHA can partially supply respiration. Table 2 reports the measurements of AdN contents and AEC of maize root tips incubated for 48 $\mathrm{h}$ in media of different composition. After a $48 \mathrm{~h}$ starvation period, total AdN content decreased but ATP/ADP and ATP/AMP ratios and AEC did not change significantly. This result confirms that in normoxic tissues the energetic status of the cell does not depend on the amount of carbon supply (Brouquisse et al. 1991, 2001; Pradet and Raymond 1983). Glyc induced a significant decrease in the total AdN pool, and the ATP/ADP and ATP/AMP ratios decreased markedly in comparison to carbon-starved or control root tips (Table 2). Such a Glyc effect could be attributed to a potential limitation of $\mathrm{Pi}$ because of glycerol-3-P (Glyc3P) accumulation. However, the addition of $10 \mathrm{mM} \mathrm{Pi}$ in the culture medium did not change significantly (less than $10 \%$ ) either the energetic status, or the respiration rate of the root tips (data not shown). Conversely to Glyc, DHA did not affect total AdN content, but the ATP/ADP and ATP/AMP ratios increased in comparison to the control (Table 2). In both Glyc-fed and DHA-fed root tips 
AEC values were only marginally affected and remained in the range found in normal plant material (Pradet and Raymond 1983). To test the potential toxicity of Glyc and DHA the growth and the respiratory metabolism of maize root tips incubated in the presence of either $100 \mathrm{mM}$ Glyc + 100 mM Glc, or 100 mM DHA + 100 mM Glc was studied. In both cases, growth and respiration rates were similar to those found with $100 \mathrm{mM}$ Glc alone (data not shown), indicating that $100 \mathrm{mM}$ Glyc or DHA are not toxic for the root tips.

These data show that Glyc and DHA do not sustain the growth of root tips, but supply enough carbon skeletons to the respiration to maintain ATP-regenerating processes. However, their opposite effect on the energetic status suggests that they also have different effects on the primary metabolism, particularly on ATP-utilizing processes.

Effects of glycerol and DHA on carbon metabolism: in-vitro and in-vivo NMR studies

In-vitro ${ }^{13} \mathrm{C}$ and ${ }^{31} \mathrm{P}$ NMR spectroscopies were used to analyze the molecular composition of the acid extracts of root tips incubated 48-h in the different physiological conditions (Table 3, supplementary data file: Fig. S1 and S2). In-vivo ${ }^{31} \mathrm{P}$ NMR was also used to monitor the time course of cytoplasmic and vacuolar Pi, in parallel with respiration rate measurements (Fig. 4).

The starvation and glucose references. As established (Brouquisse et al. 2001; Cortès et al. 2003), carbon starvation was characterized by a slowdown of respiration and a marked decrease in the levels of Suc, Glc, most of the glycolytic intermediates, AdN, organic acids, and free amino acids, except asparagine (Tables 2 and 3). Conversely, phosphoryl choline (P-chol) and phosphoryl ethanolamine (P-eth), which are markers of membrane phospholipid degradation (Roby et al. 1987), asparagine (N), which is a transient marker of protein and amino acid degradation (Brouquisse et al. 1992), and vacuolar Pi clearly increased (Fig. 4a, Table 3). Hexokinase activity was found to decrease by a factor 2 in carbon-starved root tips. As previously reported (Brouquisse et al. 2001; Cortès et al. 2003), a 48 h incubation with $200 \mathrm{mM}$ Glc did not cause significant changes in metabolite content. As a consequence of Glc import and metabolism, respiration rate and G6P content moderately increased (by 10\% within $48 \mathrm{~h}$ ), and vacuolar Pi slightly decreased, whereas cytoplasmic Pi, P-chol, and asparagines remained unchanged (data not shown). In these conditions, protein turnover remained steady for $48 \mathrm{~h}$, and root tip growth occurred. For these reasons, root tips incubated with $200 \mathrm{mM}$ Glc for $4 \mathrm{~h}$ were used as control in the experiments rather than $200 \mathrm{mM}$ Glc for $48 \mathrm{~h}$. 
Effects of glycerol. Glyc and Glyc3P increased markedly reaching respectively 135.6 and 20.6 nmole per root tip (Table 3, supplementary data file: Fig.S1 and S2). The cytoplasmic concentrations of Glyc and Glyc3P were estimated to be 45 and $15 \mathrm{mM}$, respectively based on the following criteria : an even distribution of Glyc between vacuole and cytoplasm but cytoplasmic accumulation of Glyc3P (Aubert et al. 1996), and cytoplasm and vacuole occupying each $45 \%$ of the total tissue volume in the root tips (Brouquisse et al. 2001). Soluble sugars, G6P and UDP-Glc (UDPG) decreased strongly in Glyc-fed root tips (Table 3). The low levels of G6P and soluble sugars suggest an absence of carbon flux from Glyc to the upper part of the glycolysis. This is consistent with the known inhibition of G6P isomerase by Glyc3P (Aubert et al. 1996). The accumulation of Glyc and Glyc3P (Table 3) indicates that these substrates do not limit glycerol kinase and Glyc3P dehydrogenase activities, respectively. And the 6-fold increase in 3PGA and PEP contents indicates that Glyc3P dehydrogenase activity is not limiting for carbon substrate supply to the lower part of the glycolysis. However, the strong decrease in free amino acids such as alanine, glutamate and aspartate (Table 3), which are in close equilibrium with pyruvate, $\alpha$-ketoglutarate and oxaloacetate, indicated that the pool of the TCA cycle intermediates decreased. These last observations are consistent with the decline of the respiration rate to 1.26 nmole $\mathrm{O}_{2} \mathrm{~min}^{-1} \mathrm{tip}^{-1}$ (Table 2, Fig. 4b), and suggest that carbon supply to the respiration could be limited at the PK step. The significant increase in asparagine, P-chol and Peth (Table 3) clearly shows that protein and lipid degradation occurred. These data, as well as the accumulation of Pi in vacuole (Fig. 4b) and the decrease in hexokinase activity (Table 3), confirm that Glyc-fed root tips were partially carbon-starved. When root tips were supplied with $100 \mathrm{mM}$ Glyc and $100 \mathrm{mM}$ Glc no starvation symptoms were observed. Similarly, Glc substitution to Glyc in the medium triggered full recovery of respiration and growth (data not shown). These two experiments confirmed that glycerol is not toxic to the root tips.

Effects of DHA. DHA content was found to be low in root tips incubated for $48 \mathrm{~h}$ in presence of this molecule (Table 3): $9.6 \mathrm{nmol} / \mathrm{tip}$, i.e $3 \mathrm{mM}$ in average concentration. Furthermore, the growth of DHA-treated root tips was inhibited (Fig. 3) and the respiration rate decreased (Fig. 4c, Table 2). Was DHA readily taken up by the tissue and, if so, how was it metabolized?

Differing from starvation, soluble sugar concentrations decreased only by 45\%, G6P did not vary and UDPG level even increased by $50 \%$ in comparison to control (Table 3). Glyc3P increased by $50 \%$ to reach $0.64 \mathrm{nmol} / \mathrm{tip}$ (approximately $0.3 \mathrm{mM}$ in the cytoplasm). This concentration does not inhibit the G6P isomerase and DHA might supply the upper part of 
glycolysis with carbon skeletons. However it can be inferred from the absence of growth that cell wall components were not synthesized. The increase in DHA content shows that DHA uptake was not limiting for DHA kinase activity. Furthermore, the respective 3 and 1.5-fold increase in 3PGA and PEP amounts (Table 3), indicates that DHA kinase activity was not limiting for carbon substrate supply to the lower part of glycolysis. But the decrease in the respiration rate and in alanine and glutamate levels (Fig. 4c, Table 3) indicates that the carbon supply to the respiration might be limited downstream PEP, as already observed with glycerol.

The increase in Asn, P-chol and P-eth levels (Table 3, supplementary data file: Fig. S1 and S2) and the vacuolar accumulation of Pi (Fig. 4c), and the decrease in hexokinase activity (Table 3), indicate that DHA-treated root tips were carbon-starved and that proteins and lipids were degraded. However, the high Asn content (116.2 nmol/tip) associated to a limited NPB ($31 \mu$ g.tip ${ }^{-1} .48 \mathrm{~h}^{-1}$, Fig. 1 and 2, Table 1), indicates that asparagine accumulation could result not only from the catabolism of amino acids but also from the assimilation of nitrogen. Similarly, glutamine content increased by a factor of 3 (Table 3), as well as phenylalanine, tyrosine, tryptophan, threonine, valine and isoleucine contents (data not shown). This can be interpreted as follows. DHA feeds both the lower part of the glycolysis, up to PEP, and the higher part of the glycolysis up to G6P (G6P isomerase is not inhibited without a significant amount of Glyc3P). In these conditions, the pentose phosphate pathway can operate and regenerate the reducing power (NADPH) necessary for nitrate reduction and assimilation. Thus, the availability of reducing power and carbon skeletons, via PEP carboxylase (PEPCase), could explain the increased levels in asparagine, glutamine and other amino acids in a context where growth is stopped and net proteolysis is moderate (Fig. 1-3, Tables 1 and 3). Growth and respiration were normal in experiments of co-feeding (100 mM DHA + $100 \mathrm{mM} \mathrm{Glc})$ and re-feeding (100 mM Glc substitution to $100 \mathrm{mM}$ DHA). This confirmed that $100 \mathrm{mM}$ DHA is not toxic to the root tips.

Effects of glycerol and DHA on PEPCase, PK and PEP phosphatase activities

To understand the increase of PEP and 3PGA amounts in Glyc- and DHA-fed root tips, and the concomittant decrease in respiration rate, we investigated the fate of the three PEP metabolizing enzymes in position to feed carbon skeletons to the TCA cycle: PEPCase, PK and PEP phosphatase (Table 4). First, we measured their total activity in the different physiological situations. In comparison to the control, PEPCase and PK activities decreased by $45 \%$ in $48 \mathrm{~h}$ carbon-starved roots, but PEP phosphatase doubled. In either Glyc- or DHA-fed root tips 
PEPCase activity was maintained close to control level, PK activity decreased by $30 \%$, and PEP phosphatase increased as in carbon-starved roots (Table 4). Supplementation of the incubation medium containing $100 \mathrm{mM}$ Glyc with $10 \mathrm{mM}$ Pi did not change significantly the activities of the three enzymes (data not shown).

Second, we checked the effects of $\mathrm{pH}$ and various effectors on the activity of PEPCase and PK. Indeed, the post-translational regulation of these enzymes involves their sensitivity to $\mathrm{pH}$ and/or various effectors, or their phosphorylation state (Plaxton 1996). The variations in cytoplasmic and vacuolar $\mathrm{pH}$ during the time course of the experiments could be assessed using in-vivo ${ }^{31} \mathrm{P}$ NMR. Cytoplasmic $\mathrm{pH}$ values of carbon-starved, Glyc-fed and DHA-fed root tips decreased from 7.5 to 7.35 within $24 \mathrm{~h}$, whereas that of vacuolar $\mathrm{pH}$ remained stable at 5.5 (Table 3). The activities of PEPCase and PK were then measured at cytoplasmic pH (7.35), and that of PEP phosphatase at vacuolar $\mathrm{pH}$ (5.5), in the presence of different compounds in control, carbon-starved, Glyc-fed and DHA-fed root tips (Table 5). The cellular concentration of each compound was estimated from its content in the root tips (Tables 2 and 3; Fig. 4) and its potential location in the cells to determine the assay conditions. G6P, 3PGA, UDPG and ATP were considered to be located in the cytoplasm; sugars, amino acids and organic acids were estimated to be located both in the cytoplasm and the vacuole; cytoplasmic and vacuolar Pi concentrations were drawn from in-vivo NMR data. As shown in Table 5, depending on the assay conditions and in reference to standard conditions, PEPCase and PK activities were 26 to $47 \%$ inhibited and PEP phosphatase activity was 88 to $95 \%$ inhibited. The strong inhibition of PEP phosphatase was essentially due to $\mathrm{Pi}$, the vacuolar concentration of which being in the range 3 to $20 \mathrm{mM}$ (Fig. 4). These data are consistent with previous studies showing a strong sensitivity of PEPCase, PK and PEP phosphatase activities to $\mathrm{pH}$ and effector concentrations (Duff et al. 1989; Podesta and Plaxton 1994; Hu and Plaxton 1996).

Thus, taking into account both the decrease in total activity (Table 4), and the effects of $\mathrm{pH}$ and effectors (Table 5), the PK activity measured in Glyc-fed and DHA-fed root tip extracts was calculated to be 50 and $44 \%$, respectively, lower than that in control root tip extract. Similar calculations showed that PEPC activity was 26 and $20 \%$ lower in Glyc-fed and DHA-fed root tip extracts than in control root tip extract while PEP phosphatase activity was 28 and $93 \%$ higher. These results show that the activities of PEPCase, PK and PEP phosphatase depend strongly on local conditions and are lower in-vivo than when measured in optimal conditions in-vitro. They also indicate that, in Glyc- and in DHA-fed root tips, the supply of carbon substrates to 
mitochondria might be limited in-vivo at the PK step. It would be a clue for the accumulation of PEP and 3PGA and the decrease in respiration rate.

Correlation between respiration and protein degradation

The data assembled in Fig. 1, 2 and 4, and Tables 1 and 2, show (i) that PD rate is not related to global protease activities and RSIP expression level, (ii) that the changes in protein contents are representative of PD processes, and (iii) that PD rate is low when the respiration rate is high, and high when respiration rate is low. This suggested that PD processes would be related to the carbon supply to the respiration, independently of the regulation of protease expression and activity. To test this hypothesis, maize root tips were incubated for $48 \mathrm{~h}$, either without carbon source, or in the presence of various substrates (Glc, DHA, Glyc or 3-OMG) at different concentrations $(10,50,100$ and $200 \mathrm{mM})$. In each assay condition, protein content, respiration rate and EP activity were measured. Then, respiration rate and EP activity were plotted as a function of protein content (Fig. 5). It appears clearly that protein content is highly correlated to respiration rate, but not with proteolytic activity. High protein contents were indeed observed in presence of high EP activities. These observations support the hypothesis that, in limited carbon supply conditions, PD rate might be related to the carbon supply to the respiration.

\section{Discussion}

Metabolic effects of glycerol and DHA

The data presented in this work show that neither Glyc nor DHA is able to feed efficiently the carbon metabolism of excised maize root tips. With both substrates, the stop of growth (Fig. 3), the decrease in respiration rate (Fig. 4, Table 2), hexokinase activity (Table 3), glycolytic compounds and protein content (Fig. 1, Table 3), and the increase in carbon starvation markers (Fig. 4, Table 3), EP activity and RSIP expression (Fig. 1), clearly indicate that the root tips are carbon-starved.

Conversely to most yeasts that can use Glyc as a carbon substrate in aerobic conditions, plant cells do not use it efficiently as a growth substrate and their metabolism is imbalanced by Glyc. Thus, in mesophyll cells from barley leaves, Glyc triggers an accumulation of Glyc3P, at 
the expense of intracellular Pi and impairs phosphate metabolism and photosynthesis (Leegood et al. 1988). In Glyc-fed sycamore cells, the accumulation of Glyc3P led to the competitive inhibition of G6P isomerase, cystathionine synthase and threonine synthase (Aubert et al. 1994). It was correlated to an impairment of pentose phosphate pathway, nitrogen assimilation and amino acid synthesis. Intracellular autophagy was not observed in sugar-depleted cells supplied with Glyc (Aubert et al. 1994, 1996). A similar accumulation of Glyc3P was observed in maize root tips supplied with Glyc (Table 3). In this case however, respiration decreased, growth stopped and intracellular autophagy was observed. Glyc supply could not meet the demand of cell respiration in excised maize root tips, essentially because of the limitation of the carbon flux downstream PEP. A priori, Glyc-fed root tips were not limited by Pi since Pi accumulated in the vacuole during the 48-h incubation period (Fig. 4), and no significant change was observed in respiration rate, energetic status or enzyme activity when $10 \mathrm{mM}$ Pi was added to incubation medium.

The inhibition of growth and the stop of the use of sugars in the root tips incubated with DHA are puzzling (Fig. 3, Table 3). However, preliminary experiments carried out in our laboratory showed that DHA inhibits sucrose synthase activity in-vitro (R Brouquisse and M-H Andrieu unpublished observations). In-vivo, the inhibition of sucrose synthase by DHA could slow down the Suc cycle, which is ATP consuming. This would lead to the observed increase of the ATP/ADP ratio (Table 2). It should be noted that DHA concentration was low in the root tips as compared to Glyc concentration (Table 3). This indicates that DHA entering the cells is rapidly phosphorylated into DHAP, presumably by a DHA kinase (Lerner and Avron 1977). The increase in 3PGA and PEP amounts indicates that DHA transport and phosphorylation do not limit the feeding of the root tips in carbon skeletons and that respiration limitation occurs downstream PEP.

Three PEP-metabolizing enzymes are in position to feed carbon skeletons into the TCA cycle, and susceptible to be down regulated in Glyc- and in DHA-fed root tips: PEPCase, PK and PEP phosphatase. The different regulation levels and control mechanisms involved in the modulation of PEPCase and PK activity have been reviewed in the literature (Plaxton 1996, 1998). In the present study, the effects of $\mathrm{pH}$ and effectors were tested (Tables 4 and 5). We show particularly that PK, which supplies directly respiration with carbon substrates, is $50 \%$ inhibited when measured in "Glyc or DHA conditions" compared to control ones. Although we did not take into account all the regulation levels of PEPCase and PK activities, our data provide 
good arguments to explain the decrease in respiration rate in-vivo. Tissues supplied with Glyc or DHA would stop growing because of the partial inhibition of PEPCase and PK in this situation.

The increase in PEP phosphatase activity is consistent with the increase in neutral phosphatase activity previously observed in carbon-starved material (Cortès et al. 2003). In this situation, phosphatase activities are supposed to contribute remobilizing the carbon moiety of phosphorylated compounds to feed respiration in response to carbon deprivation (Cortès et al. 2003). PEP phosphatase has been shown to be up-regulated in Pi-starved plants, and to constitute a "PK bypass" to allow PEP to pyruvate conversion when ADP becomes limiting for PK activity (Duff et al. 1989, Plaxton 1998). However, in the present study, PEP phosphatase activity is strongly inhibited by high Pi concentration in the vacuole (Table 5) and its contribution to pyruvate production is probably very low.

Regulation of EP activities and RSIP

Studying the effects of mannose and 3-OMG on maize root tips metabolism we drew the conclusion that sugar-dependent EP activities and RSIP expression were regulated at the hexokinase level (Brouquisse et al. 2001; Cortès et al. 2003). The present data confirm these conclusions and suggest that no sensing step occurs downstream hexokinase for the regulation of protease expression. When root tips were incubated in the presence of Glc, EP activities and RSIP amounts remained at the control level, whereas they strongly increased in root tips either starved or incubated with mannitol, Glyc or DHA (Fig. 1). Neither Glyc nor DHA prevented protease induction and they did not limit the supply of carbon skeletons into glycolysis (Table 3). Therefore, the occurrence of a sugar sensing step downstream hexokinase (between F6P and PEP) should be excluded.

It could be argued that, in starved, Glyc-fed, or DHA-fed root tips, the decrease of the carbon flux, downstream PEP and through the respiration, could be the regulatory signal for protease expression. This is unlikely since after a $48 \mathrm{~h}$ incubation period with Glc, Glyc or DHA, no correlation between respiration rate, and EP activities and RSIP amount was observed (Fig. 1, 4 and 5, Table 2). Alternately, it has been suggested that sugar-induced changes in ATP level, ATP/ADP or ATP/AMP ratios could be regulatory signals (Halford et al. 1999). Our data rule out this hypothesis. First, protease induction occurred as much in Glyc- or starvation-treated root tips, where ATP level decreased, as in DHA-treated root tips where the ATP level increased (Fig. 1, Table 2). Second, the ATP/ADP and ATP/AMP ratios did not change significantly between 
control, Glc-fed or starved conditions when RSIP expression patterns clearly differed, or even increased in DHA-treated root tips where RSIP was strongly expressed (Fig. 1, Table 2). Previous works support these observations since energy charge or ATP/ADP ratio are independent of the carbohydrate level in normoxic plant cells (Pradet and Raymond 1983). Other studies showed that, in spite of the decrease of sugar and AdN pools, ATP/ADP ratio remained high throughout carbon starvation (Brouquisse et al. 1991; Saglio and Pradet 1980; Roby et al. 1987). It is thus unlikely that AdN levels or ratios trigger a sugar deprivation signal.

Hypothesis on the regulation of proteolysis

Although in starved material protease induction and proteolysis occur simultaneously, it appears from the present work that these two processes are not regulated in the same way in response to variations in sugar supply. Indeed, in opposition to RSIP expression, the extent of protein degradation is clearly not related to hexose phosphorylation or to hexokinase activity. In the presence of DHA, protein content only moderately decreased, whereas RSIP expression was strongly induced as in starved, mannitol- or Glyc-treated root tips (Fig. 1). Similarly, the supply of carbon skeletons to the lower part of the glycolysis does not seem to control proteolysis since significant protein degradation occurred, despite an increase in the 3PGA and PEP pools when Glyc was supplied to the roots (Fig. 1, Tables 1 and 3). Moreover, as discussed above, it is unlikely that the amounts of AdN or the ATP/ADP and ATP/AMP ratios are involved in the regulation of the proteolysis. They are not correlated to proteolytic markers when incubation conditions change (compare for instance protein content, protein turnover, nucleotide content and ATP/ADP ratio in starved, Glyc- or DHA-fed root tips in Fig. 1 and 2, Tables 1 and 2). Our data show rather that a positive correlation exists between the respiration rate and the protein content either in the control or in the starved, DHA-, Glyc- or 3-OMG-treated root tips (Fig. 5). These different results suggest that, in maize root tips, carbon starvation-induced proteolysis might be metabolically controlled after the glycolysis, downstream PEP. Such observations agree with previous work carried out with Suc-starved sycamore cells refed with either glycerol, or pyruvate (Aubert et al. 1994, 1996). In this later case, following the addition of Glyc or pyruvate in the incubation medium, the inhibition of autophagy was related to the bearing of a steady respiration rate. It was concluded that the signal giving rise to the autophagic processes (among them, vacuolar proteolysis) originates from the declining supply of respiratory substrates to 
mitochondria. Our present results give support to the hypothesis that proteolysis is metabolically controlled independently from the regulation of protease expression.

\section{Conclusion}

The data presented in this study show that when maize root tips are supplied with carbon substrates by-passing the hexokinase step such as Glyc or DHA, sugar-repressed EPs and RSIP are up-regulated. In these conditions, the extent of protein degradation is inversely related to the respiration rate. Taken together with previous studies using mannose or 3-OMG, the present results indicate that in sugar-limited maize root tips the regulation of protease (RSIP) expression and the control of protein degradation, presumably via autophagic processes, occur at different metabolic levels. We suggest that the sugar signal involved in the regulation of the protease expression is mediated by the hexokinase step, whereas a metabolic signal triggering proteolysis could be initiated downstream glycolysis. This signal might be related to the amount of carbon supply to the mitochondria.

\section{Acknowledgments}

We wish to thank Marie-Hélène Andrieu, Marie Audo, Marie-Laurence Porte, Nathalie Pochon, Baptiste Vivinus and Jérome Jaillet, who helped us to excise and analyse the about 140000 maize root tips necessary for this study and Pioneer France Maïs, Toulouse, France who generously provided the seeds. We thank Mickaël Maucourt and Jean-Luc Le Bail for their dedicated technical assistance with NMR spectrometers and the perifusion system. This work was supported in part by grants from the Institut National de la Recherche Agronomique, the Conseil Régional d'Aquitaine and the Conseil Régional Rhônes-Alpes (France). Sandra Cortès and Adeline Evrard were supported by a doctoral fellowship from the Ministère de l'Education Nationale de la Recherche et de la Technologie (France). 


\section{References}

Akoka S, Barantin L, Trierweiler M (1999) Concentration measurement by proton NMR using ERETIC method. Anal Chem 71:2554-2557

Aubert S, Gout E, Bligny R, Douce R (1994) Multiple effects of glycerol on plant cell metabolism. Phosphorus-31 nuclear magnetic resonance studies. J Biol Chem 269:2142021427

Aubert S, Gout E, Bligny R, Marty-Mazars D, Barrieu F, Alabouvette J, Marty F, Douce R (1996) Ultrastructural and biochemical characterization of autophagy in higher plant cells subjected to carbon deprivation: Control by the supply of mitochondria with respiratory substrates. J Cell Biol 133:1251-1263

Bradford MM (1976) A rapid and sensitive method for the quantification of microgram quantities of proteins utilizing the principle of protein-dye binding. Anal Biochem $72: 248-254$

Brouquisse R, Gaudillère JP, Raymond P (1998) Induction of a carbon-starvation-related proteolysis in whole maize plants submitted to light/dark cycles and to extended darkness. Plant Physiol 117:1281-1291

Brouquisse R, James F, Pradet A, Raymond P (1992) Asparagine metabolism and nitrogen distribution during protein degradation in sugar-starved maize root tips. Planta 188:384395

Brouquisse R, James F, Raymond P, Pradet A (1991) Study of glucose starvation in excised maize root tips. Plant Physiol 96:619-626

Brouquisse R, Evrard A, Rolin D, Raymond P, Roby C (2001) Regulation of protein degradation and protease expression by mannose in maize root tips. Pi sequestration by mannose may hinder the study of its signaling properties. Plant Physiol 125:1485-1498

Chevalier C, Bourgeois E, Pradet A, Raymond P (1995) Molecular cloning and characterization of six cDNAs expressed during glucose starvation in excised maize (Zea mays L.) root tips. Plant Mol Biol 28:473-485

Chiou TJ, Bush DR (1998) Sucrose is a signal molecule in assimilate partitioning. Proc Natl Acad Sci USA 95:4784-4788

Contento AL, Kim S-J, Bassham DC (2004) Transcriptome profiling of the response of Arabidopsis suspension culture cells to Suc starvation. Plant Physiol 135:2330-2347 
Cortès S, Gromova M, Evrard A, Roby C, Heyraud A, Rolin D, Raymond P, Brouquisse R (2003) In plants, 3-O-methylglucose is phosphorylated by hexokinase but not perceived as a sugar. Plant Physiol 131:824-837

Dieuaide M, Couée I, Pradet A, Raymond P (1993) Effects of glucose starvation on the oxidation of fatty acids by maize root tip mitochondria and peroxisomes: evidence for mitochondrial fatty acid $\beta$-oxidation and acyl-CoA dehydrogenase activity in a higher plant. Biochem J 296:199-207

Duff SMG, Lefebvre DD, Plaxton WC (1989) Purification and characterization of a phophoenolpyruvate phosphatase from Brassica nigra suspension cells. Plant Physiol 90:734-741

Eastmond PJ, Graham IA (2003) Trehalose metabolism: A regulatory role for trehalose-6phopshate? Curr Opin Plant Biol 6:231-235

Fujiki Y, Ito M, Nishida I, Watanabe A (2000) Multiple signaling pathways in gene expression during sugar starvation. Pharmacological analysis of din gene expression in suspensioncultured cells of Arabidopsis. Plant Physiol 124:1139-1147

Gibson S (2005) Control of plant development and gene expression by sugar signaling. Curr Opin Plant Bio 8:93-102

Graham IA, Denby KJ, Leaver CJ (1994) Carbon catabolite repression regulates glyoxylate cycle gene expression in cucumber. Plant Cell 6:761-772

Halford NG, Purcell PC, Hardie DG (1999) Is hexokinase really a sugar sensor in plants ? Trends Plant Sci 4:117-120

Hanaoka H, Noda T, Shirano Y, Kato T, Hayashi H, Shibata D, Tabata S, Ohsumi Y (2002) Leaf senescence ans starvation-induced chlorosis are accelerated by the disruption of an Arabidopsis autophagy gene. Plant Physiol 129:1181-1193

Hanson RW (2000) Nutrient control of gene transcription. J Biol Chem 275:30747

Hebers K, Meuwly P, Frommer WB, Métraux J-P, Sonnewald U (1996) Systemic acquired resistance mediated by the ectopic expression of invertase :possible hexose sensing in the secretory pathway. Plant Cell 8:793-803

Ho S-L, Chao Y-C, Tong W-F, Yu S-M (2001) Sugar co-ordinately and differentially regulates growth- and stress-related gene expression via a complex signal transduction network and multiple control mechanisms. Plant Physiol 125:877-890

Hu Z, Plaxton WC (1996) Purification and characterization of cytosolic pyruvate kinase from leaves of the castor oil plant. Arch Biochem Biophys 333:298-307 
James F, Brouquisse R, Pradet A, Raymond P (1993) Changes in proteolytic activities in glucose-starved maize root tips. Regulation by sugars. Plant Physiol Biochem 31:845-856

James F, Brouquisse R, Suire C, Pradet A, Raymond P (1996) Purification and biochemical characterization of a vacuolar serine endopeptidase induced by glucose starvation in maize roots. Biochem J 320:283-292

Jang JC, Sheen J (1994) Sugar sensing in higher plants. Plant Cell 6:1665-1679

Jang JC, Sheen J (1997) Sugar sensing in higher plants. Trends Plant Sci 2:208-214

Koch K (2004) Sucrose metabolism: regulatory mechanisms and pivotal roles in sugar sensing and plant devopment. Curr Opin Plant Biol 7:235-246

Lee EJ, Koizumi N, Sano H (2004) Identification of genes that are upregulated in concert during sugar depletion in Arabidopsis. Plant Cell Env 27:337-345

Leegood RC, Labate CA, Huber SC, Neuhaus HE, Stitt M (1988) Phosphate sequestration by glycerol and its effects on photosynthetic carbon assimilation by leaves. Planta 176

Lerner HR, Avron M (1977) Dihydroxyacetone kinase activity in Dunaliella parva. Plant Physiol 59:15-17

Martin T, Hellman H, Schmidt R, Willmitzer L, Frommer W (1997) Identification of mutants in metabolically regulated gene expression. Plant J 11:53-62

Moore B, Zhou L, Rolland F, Hall Q, Cheng W-h, Liu Y-X, Hwang I, Jones T, Sheen J (2003) Role of the Arabidopsis glucose sensor HXK1 in nutrient, light, and hormonal signaling. Science 300:332-336

Moriyasu Y, Ohsumi Y (1996) Autophagy in tobacco suspension-cultured cells in response to sucrose starvation. Plant Physiol 111:1233-1241

Ozcan S, Johnston M (1999) Function and regulation of yeast hexokinase transporters. Microbiol Mol Biol Rev 63:554-569

Plaxton WC (1996) The organization and regulation of plant glycolysis. Ann Rev Plant Physiol Plant Mol Biol 47:185-214

Plaxton W (1998) Metabolic aspects of phosphate starvation in plants. In Lynch JP, Deikman J (eds) Phosphorus in plant biology: Regulatory roles in molecular, cellular, organismic and ecosystem processes. American Society of Plant Physiologists, Rockville, pp 229-241

Podesta FE, Plaxton WC (1994) Regulation of cytosolic carbon metabolism in germinating Ricinus communis cotyledons. 2. Properties of phosphoenolpyruvate carboxylase and cytosolic pyruvate kinase associated with the regulation of glycolysis and nitrogen assimilation. Planta 194:381-387 
Pradet A, Raymond P (1983) Adenine nucleotide ratios and adenylate energy charge in energy metabolism. Ann Rev Plant Physiol 34:199-224

Price J, Laxmi A, Martin SKS, Jang J-C (2004) Global transcription profiling reveals multiple sugar signal transduction mechanisms in Arabidopsis. Plant Cell 16:2128-2150

Roby C, Martin J-B, Bligny R, Douce R (1987) Biochemical changes during sucrose deprivation in higher plant cells; Phosphorus-31 nuclear magnetic resonance studies. J Biol Chem 262:5000-5007

Roitsch T, Balibrea ME, Hofmann M, Proels M, Sinha AK (2003) Extracellular invertase: key metabolic enzyme and PR protein. J Exp Bot 54:513-524

Roitsch T, Bittner M, Godt D (1995) Induction of apoplastic invertase of Chenopodium rubrum by D-glucose and a glucose analog and tissue-specific expression suggest a role in sinksource regulation. Plant Physiol 108:285-294

Rolland F, Moore B, Sheen J (2002) Sugar sensing and signaling in plants. Plant Cell 2002:S185-S205

Rolland F, Winderickx J, Thevelein JM (2001) Glucose-sensing mechanisms in euckaryotic cells. Trends Biochem Sci 26:310-317

Rolletschek H, Weschke W, Weber H, Wobus U, Borisjuk L (2004) Energy state and its control on seed development: starch accumulation is associated with high ATP and step oxygen gradients within barley grains. J Exp Bot 55:1351-1359

Rook F, Gerrits N, Kortstee A, Vankampen M, Borrias M, Weisbeek P, Smeekens S (1998) Sucrose-specific signalling represses translation of the Arabidopsis ATB2 bZIP transcription factor gene. Plant J 15:253-263

Sadka A, DeWald DB, May GD, Park WD, Mullet JE (1994) Phosphate modulates transcription of soybean VspB and other sugar-inducible genes. Plant Cell 6:737-749

Saglio P, Pradet A (1980) Soluble sugars, respiration, and energy charge during aging of excised maize root tips. Plant Physiol 66:516-519

Saier MH, Chauvaux S, Deutscher J, Reizer J, Ye JJ (1995) Protein phosphorylation and regulation of carbon metabolism in Gram-negative versus Gram-positive bacteria. Trends Biochem Sci 20:267-271

Schaller A (2004) A cut above the rest: the regulatory function of plant proteases. Planta 220:183-187 
Schluepmann H, Penny T, van Dijken AJ, Smeekens SC, Paul M (2003) Trehalose-6-phosphate is indispensable for carbohydrate utilization and growth in Arabidopsis thaliana. Proc Natl Acad Sci USA 100:6849-6854

Sheen J (1994) Protein phosphatase activity is required for light-inducible gene expression in maize. EMBO J 12:3497-3505

Smalle J, Viestra RD (2004) The ubiquitin 26S proteasome proteolytic pathway. Ann Rev Plant Biol 55:555-590

Stitt M, Krapp A, Klein D, Röper-Schwarz U, Paul M (1995) Do carbohydrates regulate photosynthesis and allocation by altering gene expression? In Madore MA, Lucas WJ (eds) Carbon partitioning and source-sink interactions in plants. American Society of Plant Physiologists, Rockville, pp 68-77

Vogt AM, Ackermann C, Noe T, Jensen D, Kubler W (1998) Simultaneous detection of high energy phosphates and metabolites of glycolysis and the Krebs cycle by HPLC. Biochem Biophys Res Comm 248:527-532

Yu S-M (1999) Cellular and genetic responses of plants to sugar starvation. Plant Physiol 121:687-693 


\section{Figure legends}

Fig. 1a, b Effects of Glyc and DHA on protein content, proteolytic activities and RSIP expression in maize root tips. Incubation of freshly excised root tips during $4 \mathrm{~h}$ in $200 \mathrm{mM}$ Glc defined the control $(\mathrm{Ctrl})$. Otherwise, excised root tips were incubated for $48 \mathrm{~h}$ without carbon substrate (Star), with $200 \mathrm{mM}$ Glc or in the presence of 10, 50, 100 or $200 \mathrm{mM}$ Glyc or DHA, and analyzed for proteins and EP activities (a) and RSIP abundance by Western-Blot (b) as described in Materials and methods. b Total protein from one root tip equivalent (between 136 and $64 \mu \mathrm{g}$ protein according to a) were loaded on each lane for Western-blot RSIP analysis. The percentage of RSIP specific EP activity in control (Ctrl), $200 \mathrm{mM} \mathrm{Glc-fed} \mathrm{(Glc),} \mathrm{starved} \mathrm{(Star),}$ and $100 \mathrm{mM}$ Glyc- or DHA-fed root tips was measured after immunoprecipitation experiments with anti-RSIP antibodies, as described in Materials and methods. Data are the mean of 7 (protein), 5 (EP activities) and 2 (immunoprecipitation) independent experiments. Standard deviations are below 15\%. Significant difference of $5 \%(\mathrm{x})$, and no significant difference (y), when compared to each other according to Student t-test

Fig. 2 Effects of starvation, Glyc and DHA on the turnover of proteins in maize root tips. Root tips were incubated for $24 \mathrm{~h}$ in the presence of $200 \mathrm{mM} \mathrm{Glc}$ and either $\left[{ }^{35} \mathrm{~S}\right]$-methionine or $\left[{ }^{14} \mathrm{C}\right]$ leucine, and then transferred (arrow) for $48 \mathrm{~h}$ in medium either without carbon source, or containing $100 \mathrm{mM}$ Glyc or $100 \mathrm{mM}$ DHA. Every $6 \mathrm{~h}$, proteins were extracted and amount and radioactivity were measured. Protein synthesis (hatched bars), protein degradation (open bars) and net protein balance (black bars) were calculated as indicated in Materials and Methods. This is a representative experiment out of four independent experiments

Fig. 3 Growth of excised maize root tips in different nutritive media. The maize root tips were prepared as described under "Materials and Methods" and six batches were incubated either without carbon source, or with Glc, Glyc or DHA at the indicated concentration. Each point was obtained from a sample of 20 root tips. Data are the mean \pm SD of two independent experiments

Fig. 4a-c Time courses of respiration, of cytoplasmic and vacuolar Pi in excised maize root tips. Respiration rate and in-vivo Pi concentrations were measured as described in Materials and methods and plotted as a function of the incubation time. The composition of the external medium is starvation (a), $100 \mathrm{mM}$ Glyc (b) and $100 \mathrm{mM}$ DHA (c). Cyt-Pi, cytoplasmic Pi; Vac$\mathrm{Pi}$, vacuolar Pi. Data are the mean $\pm \mathrm{SD}$ of three independent experiments 
Fig. 5 Correlation plots of protein content with either respiration, or endopeptidase activity, of excised maize root tips incubated in different nutritive media. Excised maize root tips were incubated either for $4 \mathrm{~h}$ in a medium containing $200 \mathrm{mM} \mathrm{Glc} \mathrm{(Control),} \mathrm{or} \mathrm{for} 48 \mathrm{~h}$ in a medium containing either no carbon substrate, or Glc, or Glyc, or DHA, or 3-O-methylglucose, each substrate at 10, 50, 100 or $200 \mathrm{mM}$. Closed symbols, respiration; open symbols, endopeptidase activity. EP, endopeptidase. Data are from 5 independent experiments 


\section{Supplemental data file}

Fig. S1 Sugar (a) and amino acid (b) regions of ${ }^{1} \mathrm{H}$ decoupled ${ }^{13} \mathrm{C}$ NMR spectra of acid extracts of excised maize root tips. Excised maize root tips were incubated either for $4 \mathrm{~h}$ in a medium containing $200 \mathrm{mM} \mathrm{Glc}$ (Control), or for $48 \mathrm{~h}$ in a medium containing no carbon substrate (Starvation), 100 mM Glyc or 100 mM DHA. Suc, sucrose; Fru, fructose; Glc, glucose; A, alanine; E, glutamate; N, asparagine; P, proline; Q, glutamine, tACN, trans-aconitate. Spectra were acquired at $100.61 \mathrm{MHz}$ with a FID resolution of $0.7 \mathrm{~Hz}$, a $60^{\circ} \mathrm{RF}$ pulse (10 $\left.\mu \mathrm{s}\right)$ and 2048 transients repeated every $3.5 \mathrm{~s}$. Exponential apodisation $(0.5 \mathrm{~Hz})$

Fig. S2 Phosphoesters region of ${ }^{1} \mathrm{H}$ decoupled ${ }^{31} \mathrm{P}$ NMR spectra of acid extracts of excised maize root tips:. Excised maize root tips were incubated either for $4 \mathrm{~h}$ in a medium containing $200 \mathrm{mM}$ Glc (control), or for $48 \mathrm{~h}$ in a medium containing no carbon substrate (starvation), $100 \mathrm{mM}$ Glyc or 100 mM DHA. Pi, inorganic phosphate; G6P, glucose-6-P; Glyc3P, Glyc-3-P; 3PGA, 3phosphoglyceric acid; P-eth, phosphorylethanolamine; P-chol, phosphorylcholine. Spectra were acquired at $162 \mathrm{MHz}$ with a FID resolution of $0.6 \mathrm{~Hz}$, a $60^{\circ}$ pulse angle $(15 \mu \mathrm{s})$ and 2048 transients repeated every $3.5 \mathrm{~s}$. Exponential apodisation $(0.5 \mathrm{~Hz})$ 

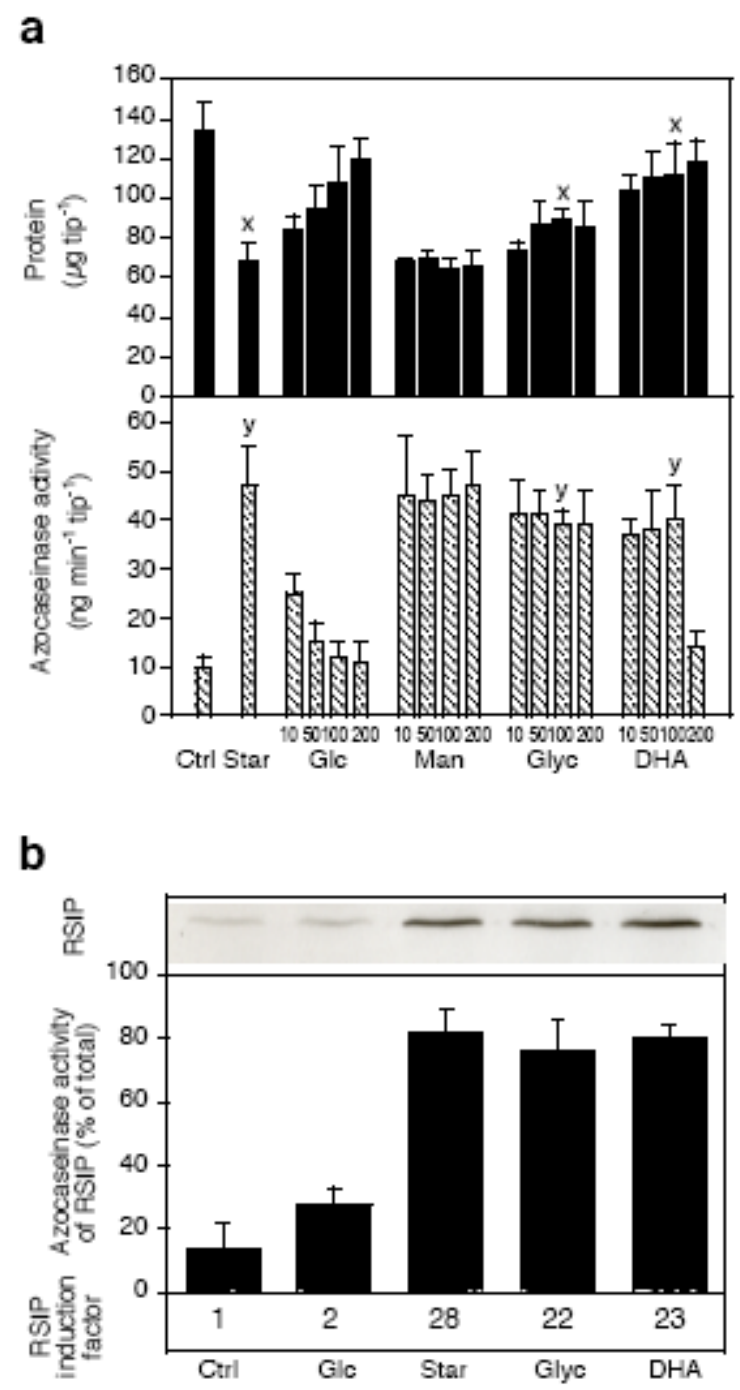

Flg 1 

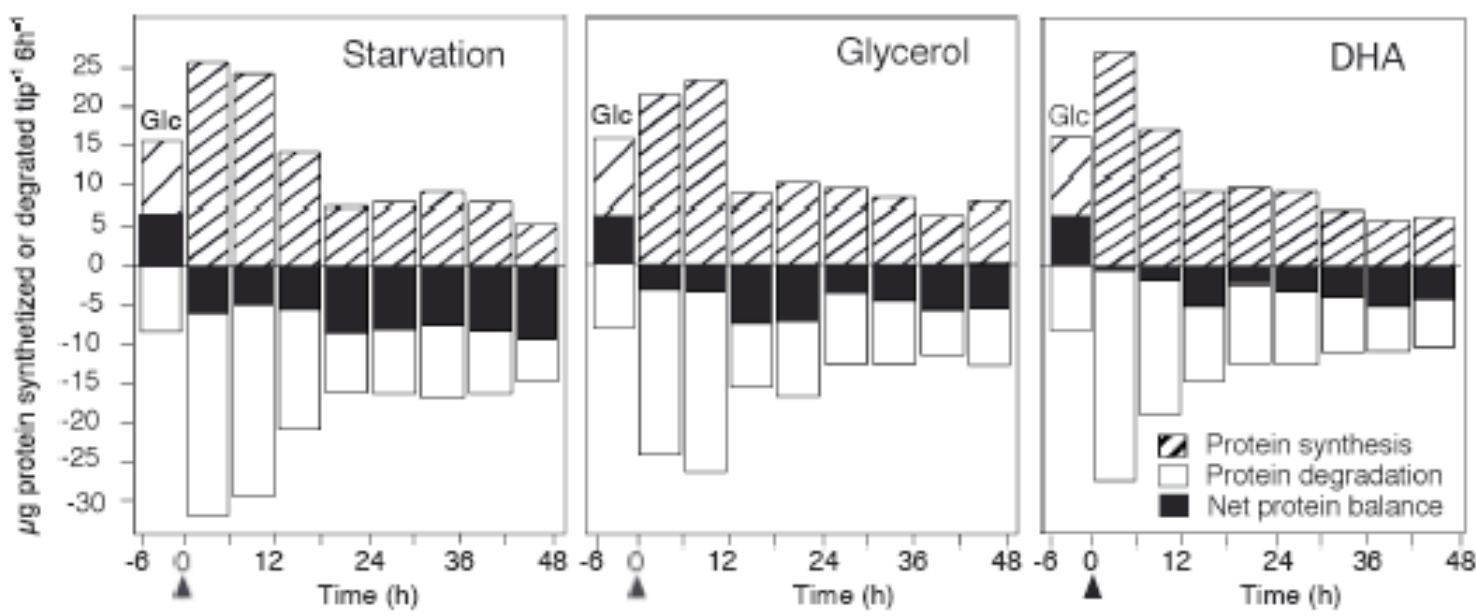

Flg 2 


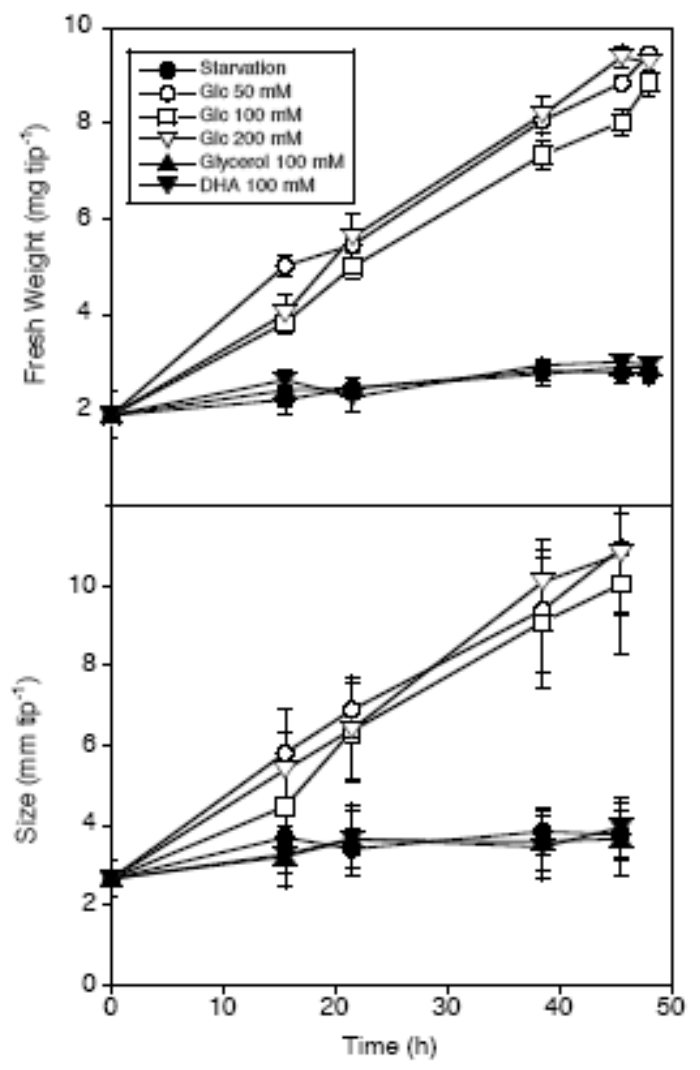

Flg 3 


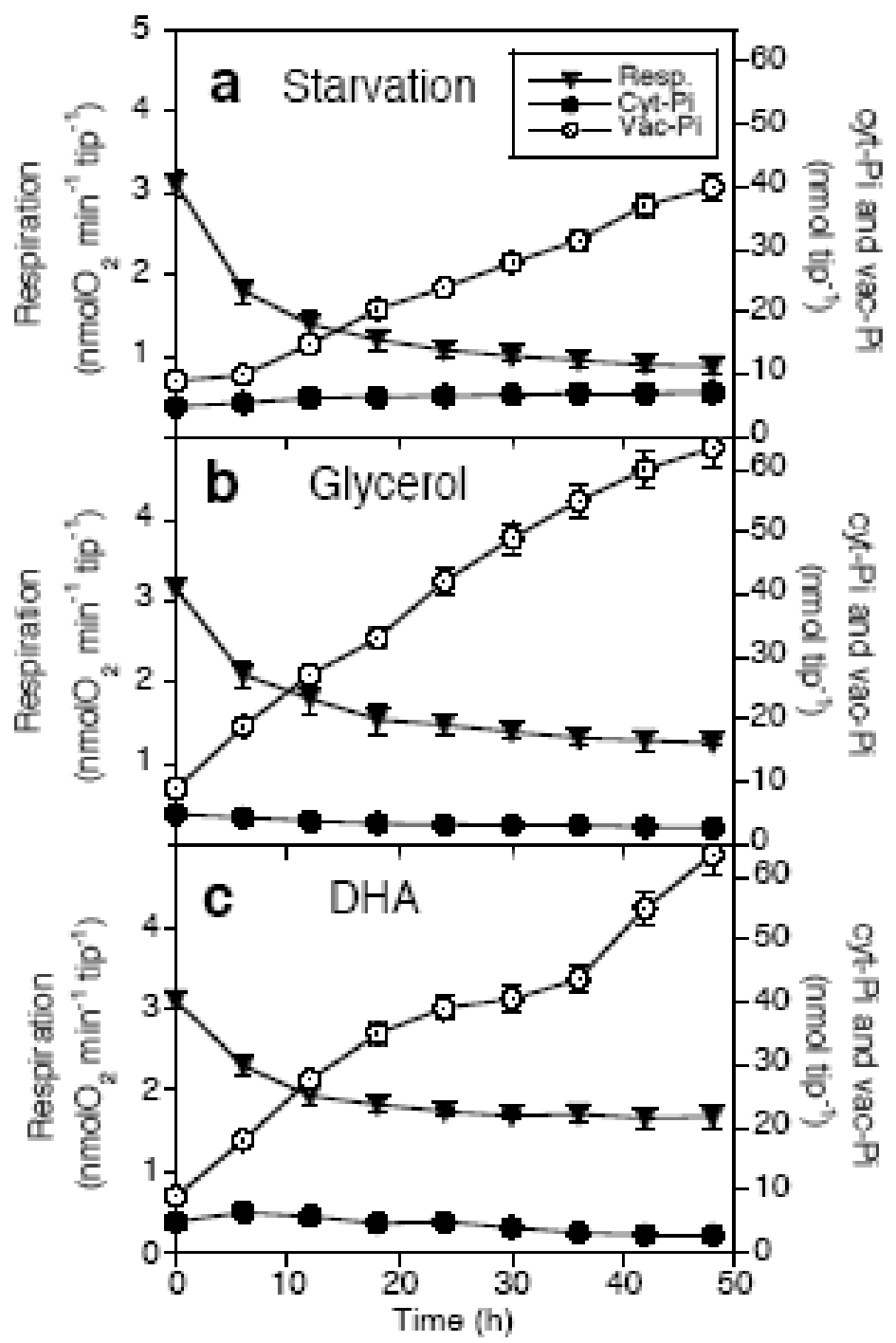

Flg 4 


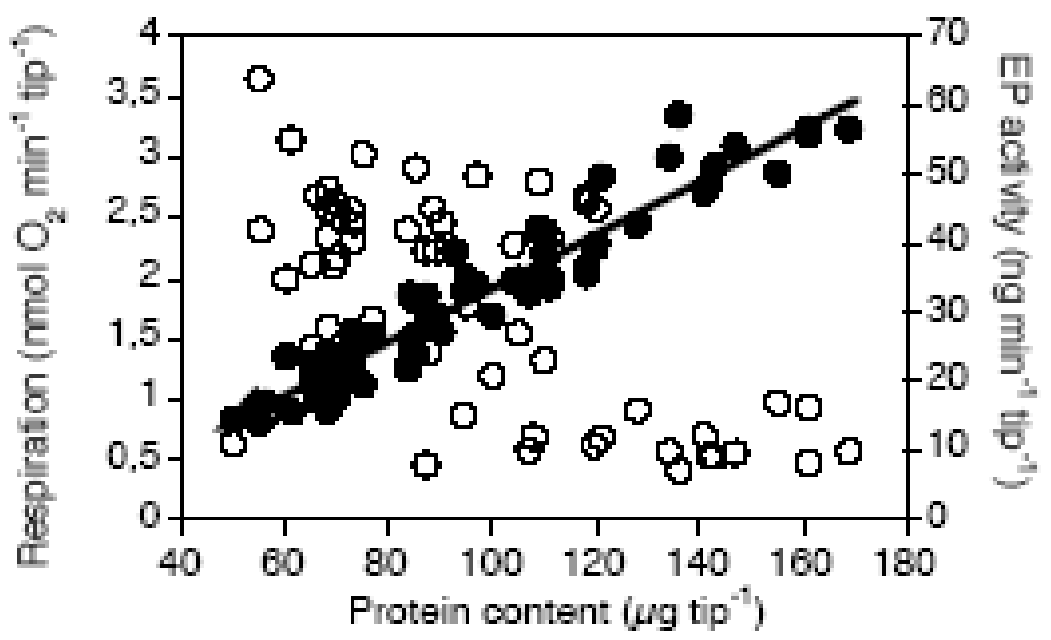

Flg 5 


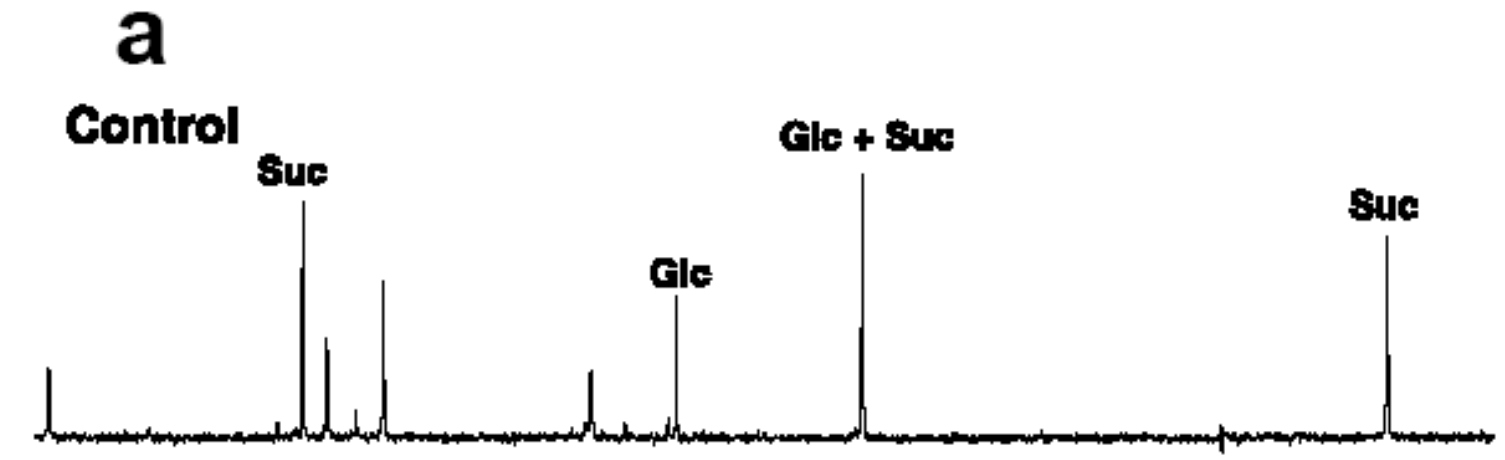

48h

Starvation
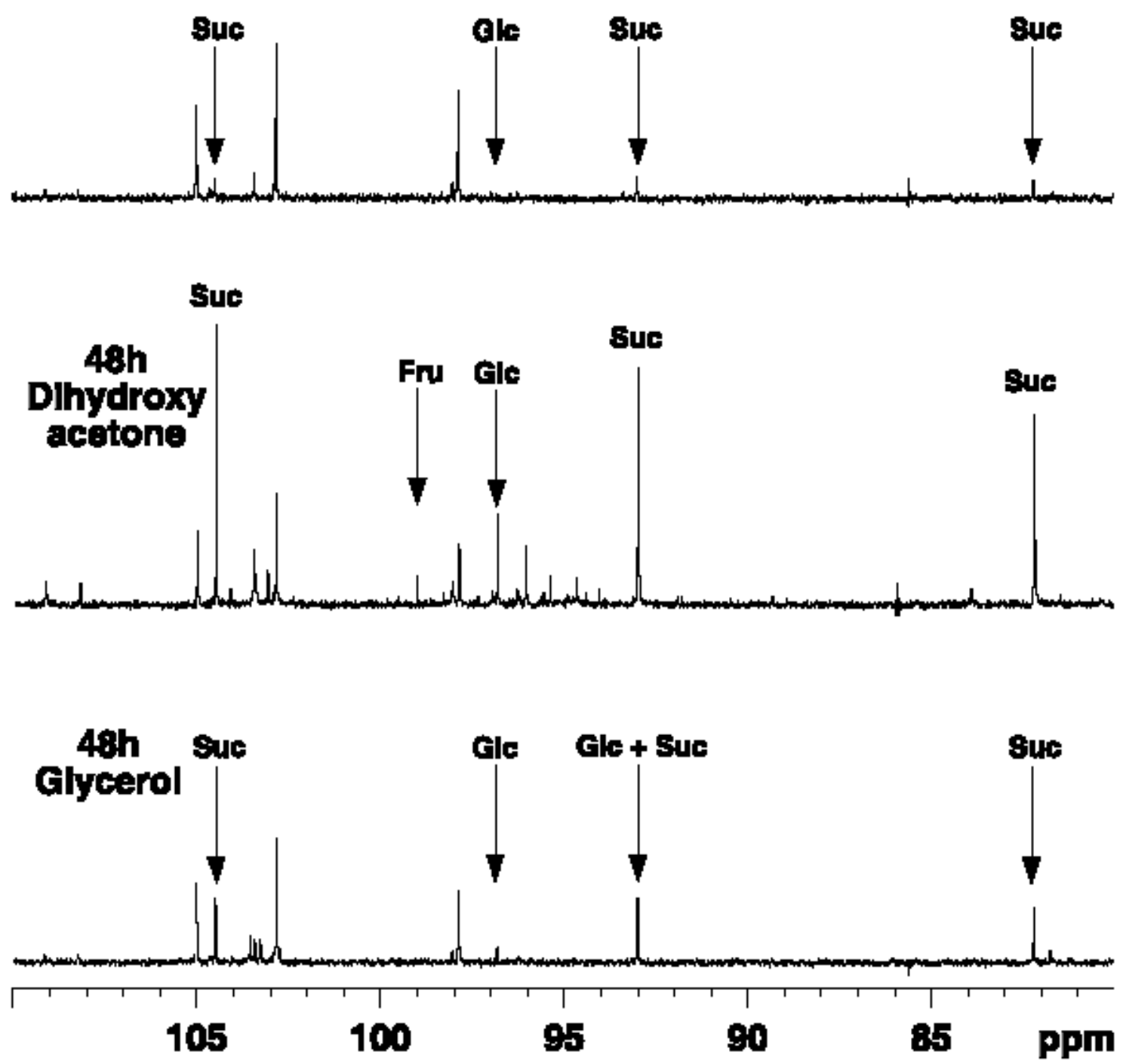

Fig S1a 

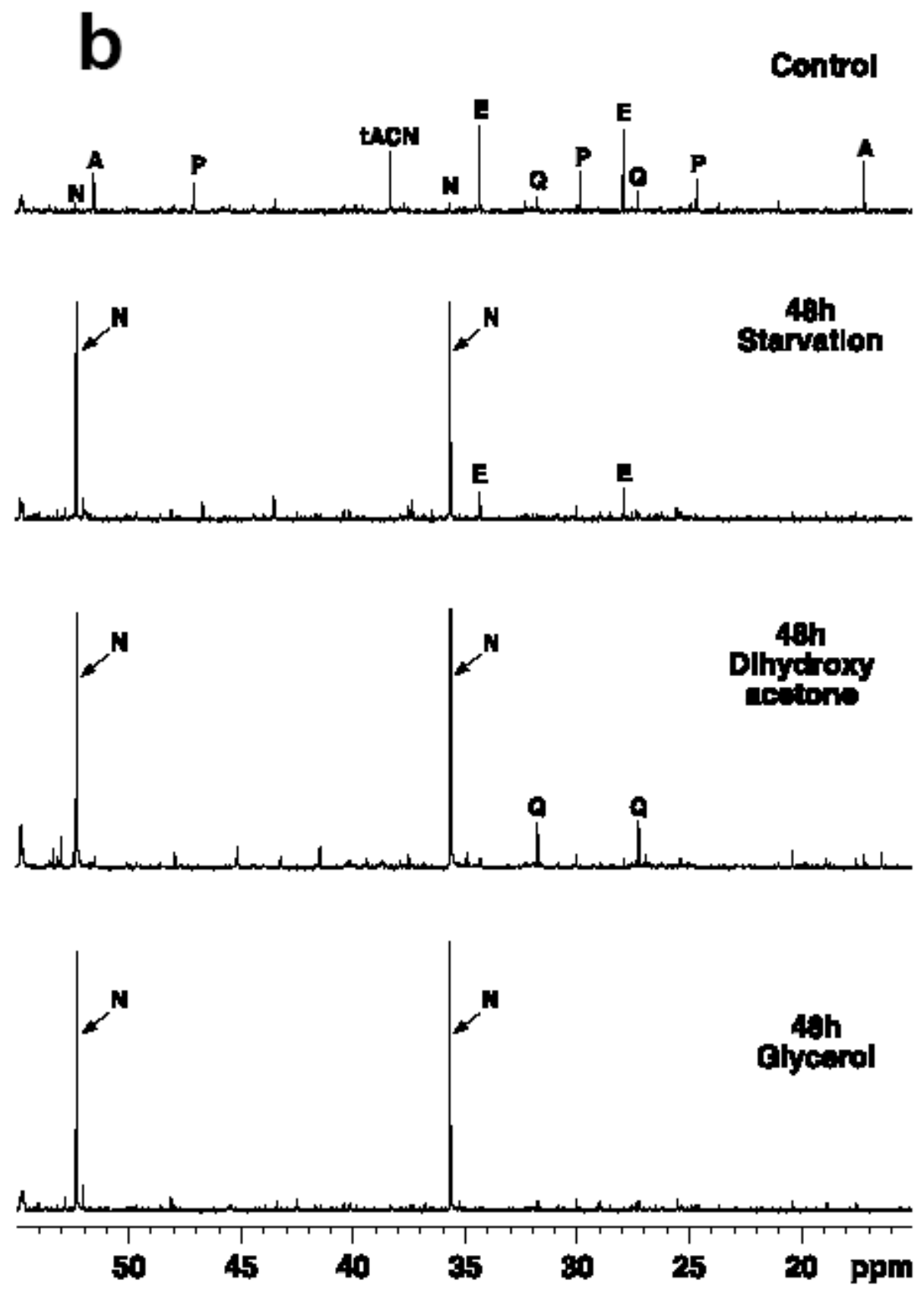

Fig S1b 


\section{Cantrol}
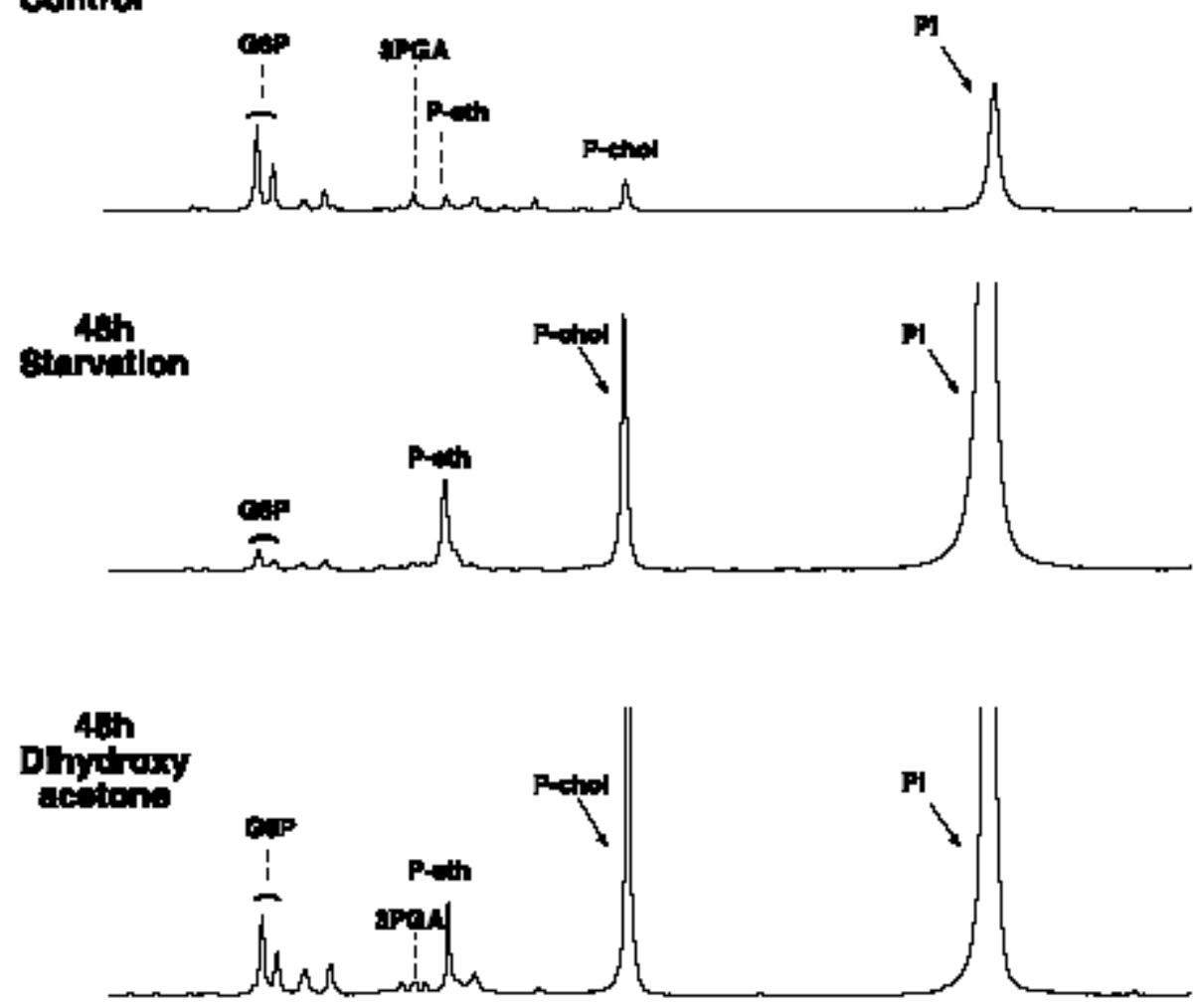

\section{4th}

Glyoorel

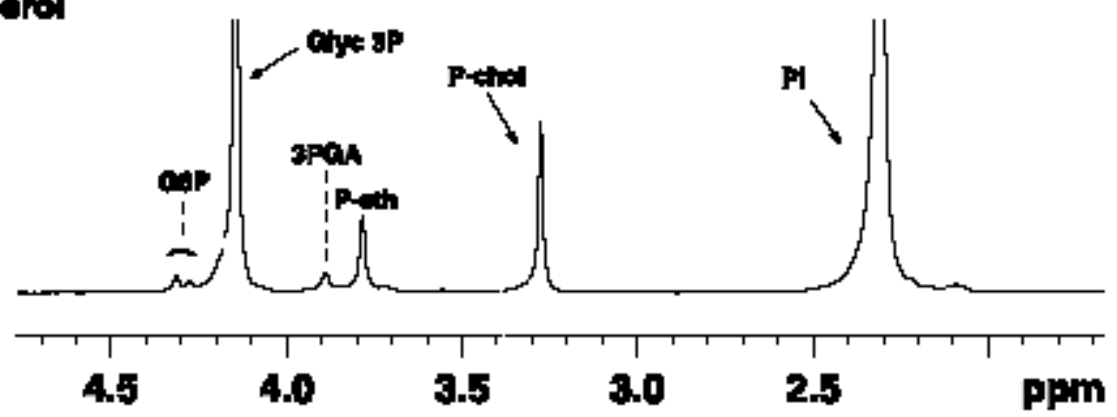

Fig S2 